\title{
1 Comparative single-cell transcriptomics of complete insect nervous
} systems

3

Benjamin T. Cocanougher $r^{1,2,8}$, Jason D. Wittenbach ${ }^{1,8}$, Xi Salina Long $^{1,8}$, Andrea B. $\mathrm{Kohn}^{3}$, Tigran P. Norekian ${ }^{3,4}$, Jinyao Yan ${ }^{1}$, Jennifer Colonell ${ }^{1}$, Jean-Baptiste Masson ${ }^{6}$, James W. Truman ${ }^{1}$, Albert Cardona ${ }^{1,5}$, Srinivas C. Turaga ${ }^{1}$, Robert H. Singer ${ }^{1,7,9}$, Leonid L. Moroz ${ }^{3,5,9^{*}}$, Marta Zlatic ${ }^{1,2,9,10^{*}}$

\section{Affiliations:}

${ }^{1}$ Howard Hughes Medical Institute Janelia Research Campus, Ashburn, Virginia, USA.

${ }^{2}$ Department of Zoology, Cambridge University, Cambridge, UK.

${ }^{3}$ Department of Neuroscience and Whitney Laboratory for Marine Biosciences, University of Florida, Gainesville/St. Augustine, Florida 32080, USA.

${ }^{4}$ Institute of Higher Nervous Activity and Neurophysiology, Russian Academy of Sciences, Moscow, Russia.

${ }^{5}$ Department of Physiology, Development, and Neuroscience, Cambridge University, Cambridge, UK.

${ }^{6}$ Decision and Bayesian Computation, Institut Pasteur, CNRS USR 3756, Department of Computational Biology and Neuroscience, Paris, France.

${ }^{7}$ Department of Anatomy and Structural Biology, Albert Einstein College of Medicine, Bronx, New York, USA.

${ }^{8}$ These authors contributed equally

${ }^{9}$ These authors contributed equally

${ }^{10}$ Lead Contact

"Corresponding author. Email: moroz@whitney.ufl.edu (L.L.M.); zlaticm@janelia.hhmi.org (M.Z.) 


\section{Summary:}

36 Molecular profiles of neurons influence information processing, but bridging the gap

37 between genes, circuits, and behavior has been very difficult. Furthermore, the

38 behavioral state of an animal continuously changes across development and as a result

39 of sensory experience. How behavioral state influences molecular cell state is poorly

40 understood. Here we present a complete atlas of the Drosophila larval central nervous

41 system composed of over 200,000 single cells across four developmental stages. We

42 develop polyseq, a python package, to perform cell-type analyses. We use single-

43 molecule RNA-FISH to validate our scRNAseq findings. To investigate how internal

44 state affects cell state, we optogentically altered internal state with high-throughput

45 behavior protocols designed to mimic wasp sting and over activation of the memory

46 system. We found nervous system-wide and neuron-specific gene expression changes.

47 This resource is valuable for developmental biology and neuroscience, and it advances

48 our understanding of how genes, neurons, and circuits generate behavior. 


\section{Introduction:}

67 Making sense of any complex system involves identifying constituent elements and understanding their individual functions and interactions. Neural circuits are no exception. While recent advances in connectomics (White et al., 1986; Jarrell et al.,

70 2012, Helmstaedter et al., 2013; Takemura et al., 2013; Ohyama et al., 2015; Berck et

71 al., 2016; Eichler et al., 2017; Hildebrand et al., 2017; Eschbach et al., 2019) and live

72 imaging techniques (Ahrens et al., 2013; Prevedel et al., 2014; Chhetri et al., 2015;

73 Lemon et al., 2015; Grimm et al., 2017; Vladimirov et al., 2018) offer unprecedented

74 information about neural connectivity and activity, the task of identifying cell types has

75 traditionally relied on painstaking morphological, functional, or single gene

76 histochemical taxonomy. High-throughput single-cell RNA sequencing (scRNAseq)

77 offers a new way forward by providing a molecular-level identity for each cell via its

78 transcriptomic profile. Importantly, it is also scalable to populations of millions of cells

79 without incurring exorbitant costs. These techniques have already revealed striking

80 heterogeneity in cell populations that is lost in bulk samples. In the fruit fly, efforts are

81 already well underway to produce connectomic (Takemura et al., 2013; Ohyama et al.,

82 2015; Berck et al., 2016; Eichler et al., 2017; Eschbach et al., 2019), activity (Chhetri et

83 al., 2015; Lemon et al., 2015; Grimm et al., 2017; Vladimirov et al., 2018), and behavior

84 atlases (Vogelstein et al., 2014; Robie et al., 2017) of the nervous system. Much work

85 has separately revealed the role that genes (Konopka and Benzer, 1971; Sokolowski

86 2001) and circuits (Garcia-Campmay et al., 2010, Borst 2014) play in behavior; a major

87 challenge is to combine genes, circuits, and behavior all at once. Single-cell analyses

88 have been performed in parts of adult (Croset et al., 2018; Davie et al., 2018;

89 Konstantinides et al., 2018) Drosophila central brain and optic lobe. One study has

90 investigated a small sample of the larval central brain (Alvalos et al., 2019). A

91 comprehensive transcriptomic atlas of the complete central nervous system is the

92 missing piece to the connectivity, activity, and behavior maps that would create the

93 required resource necessary to understand the complex interplay between genes,

94 circuits, and behavior. 
96 To this end, we developed a protocol to capture, sequence, and transcriptionally classify

97 the molecular cell types and cell states of the entire central nervous system of the

98 Drosophila larva. We did this across 4 different life stages, providing a developmental

99 profile of gene expression. Given that the Drosophila larva has a nervous system of

100 approximately 10,000-15,000 neurons (Hartenstein and Campos-Ortega, 1984;

101 Hartenstein et al., 1987; Truman et al., 1993; Scott et al., 2001), our atlas of 202,107

102 cells has up to 20X coverage of the entire nervous system and is the largest sequencing

103 effort in Drosophila to date. All previously identified cell types were recognizable in our

104 atlas, including motor neurons, Kenyon cells of the mushroom body, insulin-producing

105 cells, brain dopaminergic and serotonergic cells, and all glial subtypes.

107 While scRNAseq provides nearly complete information about the transcriptional

108 program being used by a cell at the time of collection, a drawback to the technique is a

109 loss of spatial information. We therefore used a recently developed RNA fluorescent in

110 situ hybridization (RNA-FISH) protocol to resolve the anatomical location of molecular

111 cell types in the whole larval brain (Long et al., 2017). We combined RNA-FISH with

112 high-resolution Bessel beam structured illumination microscopy to detect and count

113 individual mRNAs within newly identified cells. This technique provides ground truth for

114 the absolute number of a particular RNA in a given molecular cell type at a particular

115 time point. It also provides an opportunity to assess the quantitative capability of our

116 scRNAseq approach.

118 Larval behavior after hatching is dominated by feeding; when a critical weight is

119 achieved, this behavior switches to "wandering" in preparation for pupation (Bakker et

120 al., 1953). Endocrine and neuroendocrine pathways responsible for this switch have

121 been well characterized (Truman, 2005), but the extent of molecular changes in defined

122 cell types across the nervous system that respond to this neuroendocrine signaling are

123 not known. To investigate such nervous system-wide changes during development, we

124 sequenced the nervous system at four time points in development. 
126 Previous sensory experience alters the behavioral state of an animal. Flies that are

127 hungry form food-associated memories more easily (Krashes et al., 2009) and flies that

128 are intoxicated court more frequently (Lee et al., 2008). Male flies that lose fights are

129 more likely to subsequently exhibit submissive behaviors and to lose second contests

130 while male flies that win exhibit aggressive behavior and are more likely to win later

131 fights (Trannoy et al., 2017). Are internal states controlled transcriptionally at the level of

132 identified cell types and circuits and, if so, how? It is an open question whether memory

133 or internal state will affect gene expression globally or only in restricted cell populations.

135 In order to discover the nervous system-wide gene expression changes induced by

136 previous experience, we examined gene expression profiles from the nervous systems

137 of animals exposed to two experimental protocols. The first protocol involved presenting

138 repeated pain and fear, by mimicking repeated wasp sting. Fictive stings were induced

139 using optogenetic activation of a small population of well-described interneurons

140 (Ohyama et al., 2015). Of note, no mechanical damage to the animal's surface occurred

141 with this protocol. The second protocol involved repeated activation of higher-order

142 central brain neurons involved in learning. Using behavioral assays before and after the

143 stimulation, we showed that each of these protocols cause a long-lasting change in the

144 animals' behavioral state. We then analyzed the effect of fictive sting and repeated

145 activation of the learning center to search for changes in gene expression related to cell

146 state during behavioral learning. We consider these "cell state" genes and find that both

147 entire cell populations and individual neuron types can exhibit cell state changes.

149 Taken together, these results suggest the powerful role that transcriptomic atlases can

150 play in probing the complex interplay between cell state, circuit function, and behavior.

\section{Results:}

\section{Polyseq software performs cell type discovery}

154 A complete transcriptomic atlas of 202,107 single cells from the larval central nervous 155 system was built (Figure 1; Table S1). Nervous systems were captured at four time 156 points in development (1 hour, 24 hours, 48 hours, and 96 hours after larval hatching) 
157 and for three nervous system dissections (full CNS, brain only, and ventral nerve cord

158 only). These developmental timepoints and anatomical regions were analyzed

159 separately and in combination. Four non-neuronal and non-glial tissues, including ring

160 gland cells, hemocytes, imaginal disc cells, and salivary gland cells, were also captured

161 and analyzed as outgroups.

163 We developed polyseq (github.com/jwittenbach/polyseq), an open source Python

164 package, to perform cell type analyses. polyseq performs functions of many popular $\mathrm{R}$

165 packages such as Seurat or Monocle (Trapnell et al., 2014; Satija et al., 2015; Qui et

166 al., 2017; Cao et al., 2019) with significantly improved runtime and the extensibility and

167 modularity of Python. polyseq starts with a gene by cell matrix, which is then filtered for

168 high quality cells, normalized, regressed, reduced, and clustered. Visualization can then

169 be performed with tSNE or umap for the full dataset (Maaten and Hinton, 2008; Mclnnis

170 et al., 2018). The software also includes inbuilt functionality for violin plots and

171 heatmaps. The data remain in a form that is easy to integrate with the vast community

172 of Python packages for further visualization and analysis (full details and analysis

173 examples on github: github.com/jwittenbach/polyseq).

175 We first used polyseq to discover cell type clusters and confirmed that our findings were

176 in agreement with current state of the art analysis methods (Figure 2). In two separate

177 early third instar samples, we found the same cell types when analyzing the data in

178 Seurat, Monocle, and polyseq (Figure 2A). In these samples, the cells separated into

179 seven groups of developing neurons (which included subtypes of adult developing

180 neurons, neuroblasts, and ganglion mother cells), four groups of glia, immune cells, and

181 three groups of larval functional neurons (including distinct motor neuron and Kenyon

182 cell groupings).

183

184 To correct for batch effects, both the align function used in the monocle $\mathrm{R}$ package

185 (Haghverdi et al., 2018) and our own linear regression method in polyseq were tested

186 (Figure 2B,C). Both methods removed the visible batch effects in the umap plots (i.e.,

187 clusters that were made entirely of a single sample due to signal from separate batches 
188 collapsed into a single co-mingled population). As additional validation of cell type

189 discovery, we used Garnett, a newly developed machine learning software package in

190 R, to build a classifier based on cell type markers (Pliner et al., 2019). We found

191 consistent results with our own annotation of known and newly discovered markers for

192 larval functional neurons, neural stem cells, motor neurons, kenyon cells, and glia

193 (Figure 2D,E). Using more specific markers for known cells which are small in overall

194 number (such as insulin-producing cells, dopaminergic cells, octopaminergic cells, etc.)

195 led to overfitting of the data. These known gene markers could be used to extract cells

196 of interest without unsupervised methods.

198 Developmental profile of gene expression across four life stages

199 Given that the analysis in polyseq met the standards of current state of the art methods,

200 we moved forward with an analysis of developmental timepoints. We built atlases of the

201 entire nervous system at 1 hour, 24 hours, 48 hours, and 96 hours. Within these

202 atlases, it was clear that during development, the cellular composition of the nervous

203 system changes (Figure S1). At 1 hour, the nervous system is primarily larval functional

204 neurons. As development proceeds, the absolute number of larval functional neurons

205 remains relatively constant while the proportion of developing neurons greatly expands.

207 Having identified the main classes of cells, we investigated developmental trajectories

208 of 12,448 neural progenitor cells (NPCs) (Figure 3). We extracted and combined NPCs

209 cells from three stages of development (1 hour, 24 hours, and 48 hours) and performed

210 an analysis in Monocle (Trapnell et al., 2014; Qiu et al., 2017; Cao et al., 2019) (Figure

211 3). Garnett was used to predict cell types (Pliner et al., 2019). Known cell ages were

212 used to anchor a psuedotime analysis, which aligned the data from early to late NPCs.

213 Gene expression in these populations revealed known markers (such as insensible

214 (insb) in Ganglion Mother Cells) and unexpected markers, including long non-coding

215 RNA (CR31386 in early NBs). IGF-II mRNA-binding protein (Imp) and Syncrip (Syp)

216 form important gradients that mark NB age (Liu et al., 2015). Imp levels decrease with

217 age while Syp increases with age - young NBs have high levels of Imp and low levels of

218 Syp, intermediate NBs have intermediate levels of Imp and Syp, and older NBs have 
219 low Imp and high Syp. These waves are evident in our data and provide an opportunity

220 to investigate further temporal gene expression gradients.

222 Gene modules were discovered, which characterized populations of early, intermediate,

223 and late NPCs (Figure 3D,E; Table S2). Early NPCs were characterized by the

224 expression of genes important for genome organization, chromatin remodeling, and

225 gene splicing. This allows for a future diversity of cell function and identity. Intermediate

226 NPC gene modules were characterized by genes necessary to build neurons - these

227 included expression of genes important for protein targeting and transport and

228 neurotransmitter synthesis. Late NPCs were enriched for genes which are critical for

229 newly differentiated neurons and circuit construction; significant GO terms included

230 genes required for connecting circuits, such as axon guidance molecules and synapse

231 organization genes, and genes important for circuit function, such as genes involved in

232 memory storage.

234 Complete transcriptomic atlas of the larval central nervous system

235 Next we built an atlas of all cells captured at all stages (Figure 4). Transcriptomic cell

236 types split into seventy clusters (Table S1). These seventy cell types could be grouped

237 into many recognizable groups of cells, including: (1) adult developing brain neurons,

238 (2) adult developing VNC neurons, (3) larval functional brain neurons, (4) larval

239 functional VNC neurons, (5) motor neurons, (6) kenyon cells, (7) brain neuroblasts, (8)

240 VNC neuroblasts, (9) brain ganglion mother cells, (10) VNC ganglion mother cells, (11)

241 glia, (12) hemocytes, (13) imaginal disc cells, (14) salivary gland cells, and (15) ring

242 gland cells.

244 Larvae spend much of their life feeding and growing. From initial hatching to pupation,

245 larvae grow significantly in length and mass (Truman et al., 2005). During this growth

246 period, the larval nervous system grows and adds developing adult neurons which

247 remain quiescent during larval life but grow and elaborate their axonal and dendritic

248 arbors during pupation into adult functional neurons (Li et al., 2014). In the atlas, we can

249 identify adult developing neurons through high expression neuronal markers ( $n S y b$, 
250 elav) and a lack of synaptic and neurotransmitter genes (e.g., VChAT, VGlut). Recent

251 work in the first instar brain showed that adult developing neurons (or undifferentiated

252 neurons) express headcase ( $h d c$ ) and unkempt (unk) (Avalos et al., 2019). We see this

253 expression continues in adult developing neurons at 24 and 48 hours. Furthermore, we

254 find this group is marked by many more genes, including the actin-binding protein

255 singed (sn), the zinc finger transcription factor jim, and the transcriptional repressor

256 pleiohomeotic (pho).

258 Larval functional neurons participate in neural circuits which control sensation and

259 behavior. At larval hatching, embryonic neurons are born, and all the neurons

260 necessary for larval life are functional (Truman and Bate, 1988). These neurons will

261 continue to grow and some populations, such as the Kenyon cells of the mushroom

262 body, will add more neurons throughout development. Identifiable cells at the top level

263 include motor neurons, Kenyon cells, excitatory and inhibitory interneurons,

264 monoaminergic neurons, and neuropeptidergic neurons. A unifying feature of these

265 cells includes expression of classical Drosophila neuronal markers (nSyb, elav),

266 however, we also find many other genes that mark the larval functional neuron group

267 robustly. These markers include the transmembrane receptor protein tyrosine kinase

268 activator jelly belly (jeb), the protein tyrosine phosphatase $I A-2$, the ligand gated

269 chloride channel Resistant to dieldrin (Rd), and one of the beta subunits of sodium-

270 potassium pump (nirvana3; nrv3).

272 Monoaminergic neurons play a key role in learning in the fly (Schwaerzel et al., 2003;

273 Selcho et al., 2009). A single top-level cluster was identified with the expression of key

274 monoaminergic synthetic enzymes (Trh, ple) and transporters (DAT, SerT).

275 Subclustering of this top-level cluster revealed three strong groups, corresponding to

276 serotonergic, dopaminergic, and octopaminergic clusters, identifying previously

277 undescribed markers of these populations of cells which separate one monoamine type

278 from another (Figure S7). 
$280 \mathrm{Jhl}$-21, a solute carrier 7-family amino acid transporter, is an example of a novel marker

281 found here in 5-HT neurons. This gene encodes for a protein necessary for protein

282 nutrition signaling, which was recently described (Ro et al. 2016; Ziegler et al., 2016;

283 Ziegler et al., 2018). However, these reports describe the importance of the Jhl-21

284 protein peripherally, with no mechanism for the transmitting of nutritional information to

285 the nervous system. Here we see that $\mathrm{Jhl}-21$ is expressed in the serotonin neuron itself,

286 suggesting that serotonin neurons act directly as sensors for the amino acid nutritional

287 state.

Neural progenitor cells include neuroblasts (NBs), intermediate neural progenitors, and ganglion mother cells (GMCs) (Doe, 2017). NBs divide asymmetrically in three ways to

291 produce progeny: type 0 NBs divide into one self-renewing NB and one neuron; type 1

292 NBs divide into one NB and one GMC; type 2 NBs divide into one neuroblast and one 293 intermediate neural progenitor which then itself divides into a GMC (Doe, 2017). Each

294 GMC then divides terminally to form two neurons or one neuron and one glial cell.

295 Precisely timed patterns of temporal transcription factors guide this development. We

296 are able to investigate these patterns over space and time by collecting the brain and

297 VNC separately and collecting multiple stages of larval development (Figure 3). The

298 mushroom body continues to grow and develop during larval life. We were able to

299 identify mushroom body neuroblasts in our dataset, which were found in brain NB

300 clusters and characterized by high expression of the late neuroblast marker Syp, genes

301 for cell cycling, including pendulin (Pen) and cyclin $\mathrm{E}$ (CycE), and by the long noncoding

302 RNA pncr002:3R (Figure 4).

304 Five glial subtypes were recognizable in our atlas, including midline/cortex, astrocyte-

305 like, chiasm, peripheral/surface, and longitudinal body glia (Figure 4) (Freeman, 2015).

306 These glia were identified based on the expression of well-characterized markers, such

307 as wrapper and slit (s/i) expression in midline/cortex glia, alrm expression in astrocyte-

308 like glia, hoe1 expression in chiasm glia, swim in surface glia, and vir-1 in longitudinal

309 body glia. In addition, we find CG5955, which codes for an L-threonine 3- 
310 dehydrogenase, is highly expressed and found specifically in all glia other than

311 longitudinal body glia.

313 Hemocytes, imaginal disc, salivary gland, and ring gland cells were also captured and

314 sequenced. Hemocytes form the immune system in Drosophila. Hemocytes expressed

315 serpent (srp), the canonical marker of embryonic hemocytes (Fossett and Schulz,

316 2001). Hemocytes also had a very high expression of neuropeptide-like precursor 2

317 (Nplp2).

319 Imaginal discs are embryonic tissues that become adult tissues, such as wings and

320 legs, after metamorphosis. We dissected these cells and sequenced them separately.

321 We found high and specific expression of many uncharacterized genes, including

322 CG43679, CG14850, CG44956, and CG31698, among others (Table S1).

324 Unlike the imaginal disc, which had few genes in common with neurons, salivary gland

325 cells, surprisingly, formed a homogenous group characterized by expression of many

326 genes shared with neurons, such as the nucleo-cytoplasmic shuttling protein

327 hephaestus (heph), the RNA-binding protein Syncrip (Syp), the cadherin molecule

328 Shotgun (shg), and the cell adhesion molecule Fasciclin 3 (Fas3). Given the secretory

329 nature of the salivary gland, it would be interesting to further investigate the evolutionary

330 and developmental relationship between the salivary gland and neurons, especially

331 given that in other animals, such as molluscs, salivary gland cells are secretory and

332 have action potentials (Kater et al., 1978a,b).

334 The ring gland is critical for transitions in development. The ring gland was

335 characterized by expression of the well-described Halloween genes, including members

336 of the cytochrome P450 family required for ecdysteroid biosynthesis, including phantom

337 (phm), spook (spo), spookier (spok), disembodied (dib), shadow (sad) and shade (shd)

338 (Gilbert, 2004). The ring gland also has a high expression of the NADP/NADPH

339 phosphatase curled (cu). 


\section{Validating transcriptomic predictions}

342 Here, we used Insulin-producing cells (IPCs) as illustrative examples to validate scRNA-

343 seq data. IPCs consist of just fourteen neurons in the larval brain (Figure 5A) (Schlegel

344 et al., 2016). These cells participate in circuits which monitor the nutritional status of the

345 larva and function as the larval equivalent of the mammalian pancreas. If IPCs are

346 ablated, larvae and adults are smaller and have a diabetic phenotype, including

347 increased hemolymph trehalose and glucose levels (Rulifson et al., 2002). IPCs secrete

348 insulin-like peptides which regulate hemolymph sugar levels. Graph-based clustering

349 revealed a cluster defined by the strong expression of insulin-like peptide 2 (IIp2) and

350 insulin-like peptide 5 (IIp5) expression, which are canonical markers of IPCs (Figure

351 5B). By subsetting the data to look only at 96 cells in the putative IPCs cluster, the

352 neurotransmitters and receptors expressed by these could be analyzed (Figure 5C).

354 Previous reports show IPCs are regulated by canonical neurotransmitters. This includes

355 modulation by serotonin through the $5-\mathrm{HT} 1 \mathrm{~A}$ receptor and octopamine through the

356 Octbeta1 receptor (Luo et al., 2012) and by the neuropeptide allatostatin A (Hentze et

357 al., 2015). We confirmed this known expression of 5-HT1A and Octbeta1 receptor. In

358 our atlas, we also see the strong expression of additional (previously unknown for these

359 cells) receptors for dopamine (Dop2R), glutamate (GluClalpha), and Allatostatin C

360 Receptor 2(AstC-R2) in IPCs (Figure 5C).

362 To validate the specificity of our scRNAseq approach for identifying AstC-R2 in ICP

363 cells, we probed AstC-R2 mRNA in a HaloTag reporter line for the ICPs. The overlap

364 between the neurons containing the HaloTag and FISH signals confirmed the

365 sequencing result (Figure 5D). The colocalization of AstC-R2 with 14 IPCs suggests

366 that all ICPs are regulated by AstC through AstC-R2. The discovery of regulation by

367 AstC-R2 updates our model of the regulation of IPCs by adding an additional population

368 of cells that are modulating IPC activity.

370 Correlating smRNA-FISH and scRNAseq 
371 In order to determine whether scRNAseq could quantitatively capture the dynamics of

372 expression in a single cell, we compared scRNSeq expression to ground truth

373 expression levels determined using single-molecule RNA-FISH (smRNA-FISH) (Femino

374 et al., 1998). To make analyses more prisise and localized, we compared the RNA

375 levels in a very small population of cells discovered in our atlas that express vesicular

376 glutamate transporter (VGlut) and the neuropeptide Allatostatin C (AstC). We quantified

377 the relative expression of these mRNAs using smFISH and compared the result with

378 scRNAseq (Figure 6).

We used smFISH to probe VGlut and AstC mRNAs simultaneously and obtain quantitative expression levels. We detected 5 groups of cells that contain AstC FISH signals, which was consistent with previous reports of AstC localization (Williamson et

383 al., 2001). We observed 5 pairs of cells that contained both VGlut and AstC. Among the

3845 pairs, 1 pair belonged to previously reported SLP1 AstC cells (Figure 6A). We

385 quantified the VGlut and AstC mRNAs in these cells using a Bessel beam selective

386 plane illumination microscope (BB-SIM) (Long et al., 2017). Although quantification of

387 VGlut and AstC mRNAs within individual cell bodies could not be obtained due to the

388 difficulty of segmenting overlapping cell bodies, we were able to obtain an average

389 quantification of VGlut and AstC mRNAs within these 5 pair of cells (Figure 6B). The

390 similarity we obtained for the VGlut and AstC expression ratio between single-molecule

391 FISH and scRNAseq suggested that the relative quantification from scRNAseq was

392 compatible with single-molecule FISH (Figure 6C).

\section{Optogenetic sting alters expression globally}

395 To investigate if a change in internal state would alter nervous-system-wide gene

396 expression, we examined gene expression profiles from animals exposed to repeated

397 fictive sting. An optogenetic sting was induced by activation of the basin interneurons.

398 The basins are first order interneurons that receive input from nociceptive (pain) and

399 mechanosensory (vibration) sensory neurons (Ohyama et al., 2015). Such optogenetic

400 activation of the brain evokes a rolling escape response (Ohyama et al., 2015), which 
401 mimics the natural response to wasp sting or nociceptor activation (Hwang et al., 2007).

402 Of note, no mechanical damage was induced in our protocol.

404 The basin interneurons were activated for 15 seconds, with a 45 second rest period for

405 a total of 120 activation periods (Figure 7A). Supervised machine learning was used to

406 automatically detect behavior (Jovanic et al., 2017). A rolling escape response was

407 observed at the start of the experiment; by the final activation stimulus, backing up and

408 turning were the predominate responses (Figure 7B).

410 Control animals of the same age were collected from the same food plate as

411 experimental animals and placed on an agar plate in the dark for two hours.

412 Immediately following the sting protocol, 2-4 animals from each group underwent the

413 scRNAseq protocol. We were primarily interested in searching for cell state genes which

414 could drive cell state clustering (Figure 7D). If cells from experimental animals and

415 controls are analyzed together, will cells cluster together based on cell type

416 (independent of treatment group) or cell state (dependent on treatment group)? If cell

417 type clustering is observed, it suggests that any changes in cell state induced by our

418 protocol are minor compared to cell type-specific features. But if cell state clustering is

419 observed, it is evidence that experience driven changes are at least of comparable

420 importance to cell type in determining genetic cell state.

422 The optogenetic sting protocol led to cell state clustering. Transcriptomic data from cells

423 isolated from activated and control brains were normalized and analyzed in the same

424 mathematical space, but the clustering that was observed was based on cell state (i.e.,

425 clustering was driven by whether the cells came from a "stung" animal or an "unstung"

426 control). Cell state genes that differed between the stung and unstung controls were

427 discovered (Figure 7F).

429 Cell state genes were most evident in larval functional and developing neurons,

430 including motor neurons, cholinergic, and neuropeptidergic cells. Genes that were

431 upregulated in motor neurons following the sting protocol included non-coding RNA 
432 (CR40469), carbohydrate metabolic enzymes (lactate dehydrogenase, ImpL3), and the

433 ethanol-induced apoptosis effector, Drat.

435 In addition to cell state genes within the nervous system, a large group of immune cells

436 was sequenced in the sting state, with particularly high expression of neuropeptide-like

437 precursor 2 (NPLP2), a gene which has been observed in phagocytic immune cells

438 (Fontana et al., 2012). RNA-FISH in sting and control conditions revealed this transcript

439 is not higher in the neurons but suggested that the lymph gland is being activated and

440 ramping up cell numbers in the sting condition (Figure S8). Strong evolutionary

441 selection pressure exists on the larva to survive predation by parasitic wasps

442 (Kraaijeveld and Godfray, 1997). Larvae can survive by using their immune system to

443 encapsulate and prevent the hatching of internalized parasitic wasp eggs. Previous

444 work has investigated the role of signaling detected by mechanical damage of the sting

445 and the presence of the foreign body (wasp egg) inside the larva (Sorrentino et al.,

446 2002). Our transcriptomic data suggest the immune system may also respond to a

447 currently unknown signal generated directly by the nervous system.

\section{Learning center overactivation alters expression locally}

450 In a second behavior protocol, we activated all higher-order central brain neurons

451 involved in learning and memory, called Kenyon cells (KCs). Similar to the fictive sting,

452 we observed a change in behavioral response at the start and end of the training. At the

453 start of training, animals hunch and arrest movement at the onset of activation and

454 crawl forward at the offset of activation (Figure 7C). At the end of the training, animals

455 continue to hunch and stop at the onset, but a larger fraction ( 80\%) perform a small

456 motion before turning rather than crawling forward to offset. Also, this protocol not only

457 altered animals response to the optogenetic activation of KCs but also drastically

458 altered behavior after activation. Animals greatly increased the probability of stopping

459 and reduced the probability of crawling.

461 To discover potential molecular changes that could drive these behavioral changes, we 462 analyzed the transcriptomes of animals exposed to these optogenetic training protocols 
463 and compared them to controls. Unlike the global changes in gene expression following 464 an optogenetic sting, we detected changes in the transcriptomic state of many fewer cell

465 types following repeated activation of the higher-order brain neurons involved in

466 learning and memory (Figure 7G-I). We discovered a number of interesting candidate

467 genes that were upregulated in an activity-dependent way in Kenyon cells and

468 dopaminergic neurons, which are key cell populations in the learning and memory

469 center (Figure 7;Table S3,S4).

471 Cell state genes with differential expression between KC activated brains and controls

472 separated local groups of cells within clusters. Changes were observed in KCs and

473 dopaminergic neurons (DANs) (Figure 7H,I). Cell state genes were not limited to

474 previously described activity-related genes. They included long non-coding RNA (noe,

475 CR40469), chromatin remodeling (His2AV, mamo), axon guidance (trn, DIP1, fas,

$476 \quad d p r 14, f z 2)$, and receptor genes (Dop2R).

478 Discussion:

479 This work makes several contributions to the field. First, we present the first full 480 transcriptomic atlas of the entire central nervous system at the single-cell resolution.

481 Second, we use super-resolution microscopy to compare single-molecule RNA-FISH

482 with scRNAseq in the Drosophila larva. By combining these two techniques - the first

483 providing information about the complete collection of RNA present in a cell and the

484 second providing full anatomical, subcellular, and absolute quantification of a chosen

485 RNA(s) - we provide a resource for the field of Drosophila neurobiology and provide an

486 example of complementary methods for building and validating single-cell molecular

487 atlases. Third, we provide an experimental paradigm for discovering a molecular

488 signature of internal state and use this paradigm to uncover drastic gene-expression

489 changes that accompany a state of stress evoked by repeated "optogenetic" predator

490 attack. Our atlas is therefore a powerful resource for developmental biology,

491 neuroscience, and evolutionary biology. 
493 Separating cell type from cell state is a key challenge for transcriptomic cell atlases. In

494 order to understand the changes in a specific cell type between health and disease, for

495 example, it will be necessary to be able to find the same cell type among differing

496 conditions. Here we show that such a distinction can be discovered in cases where

497 molecular cell state is significantly altered. Furthermore, we show that even in a

498 nervous system with drastically different (and unnatural) activity patterns in a sizable

499 population of highly interconnected neurons (here 200 of 10,000 or $2 \%$ of the nervous

500 system), limited changes may be observed across the entire nervous system but

501 changes can be observed in specific cell types. We foresee such techniques being

502 useful to investigate a wide range of internal state and cell state changes, from sleep to

503 parasitism to circadian rhythms.

505 Single-cell transcriptomic atlases are the missing piece required for the combined 506 analysis of genes, circuits, and behavior. Our work here shows that transcriptomic 507 atlases can be reliably built for multiple developmental stages of the Drosophila larva.

508 Furthermore, we show that optogenetic manipulations of internal state can alter gene 509 expression in a context-dependent manner. By adding a transcriptomic atlas to the 510 existing atlases of neuron connectivity, neuron activity, and behavior, we have set the 511 stage for a more complete understanding of the principles that underlie the complex 512 interplay of genes, circuits, and behavior.

\section{Acknowledgments:}

516 We thank J. Grimm for sharing reagents; J. Etheredge for fly stocks; S. Harrison, M. 517 Mercer, and the Janelia Fly Core for assistance with fly husbandry; A. Lemire and K. 518 Aswath of Janelia Quantitative Genomics for assistance with sequencing. Funding: 519 Supported by Janelia HHMI (M.Z.), Gates Cambridge Trust (B.T.C.), HHMI Medical 520 Fellows Program (B.T.C.), NSF (1146575, 1557923, 1548121 and 1645219; L.L.M.). 
522 Author contributions: B.T.C., L.L.M., and M.Z. conceptualized the study; B.T.C.,

523 J.D.W., X.L., and J.Y. performed all data analysis and visualization; B.T.C., J.D.W., J.-

524 B.M., and J.Y. performed all software development, B.T.C., X.L., J.L., A.B.K., and

525 L.L.M. performed the investigation; B.T.C., J.D.W., and X.L. curated the data; B.T.C.,

526 X.L., A.B.K., and L.L.M. developed methodology and performed validation, R.H.S.,

527 L.L.M. and M.Z. acquired funding, provided resources, and performed project

528 administration; S.T., R.H.S., L.L.M. and M.Z. supervised the study; B.T.C., J.D.W. and

529 X.L. wrote the original draft; B.T.C., X.L., J.D.W., R.H.S., L.L.M. and M.Z. edited the

530 final manuscript; all authors reviewed the final manuscript.

532 Declaration of Interests: none.

534 Figure titles and legends: 

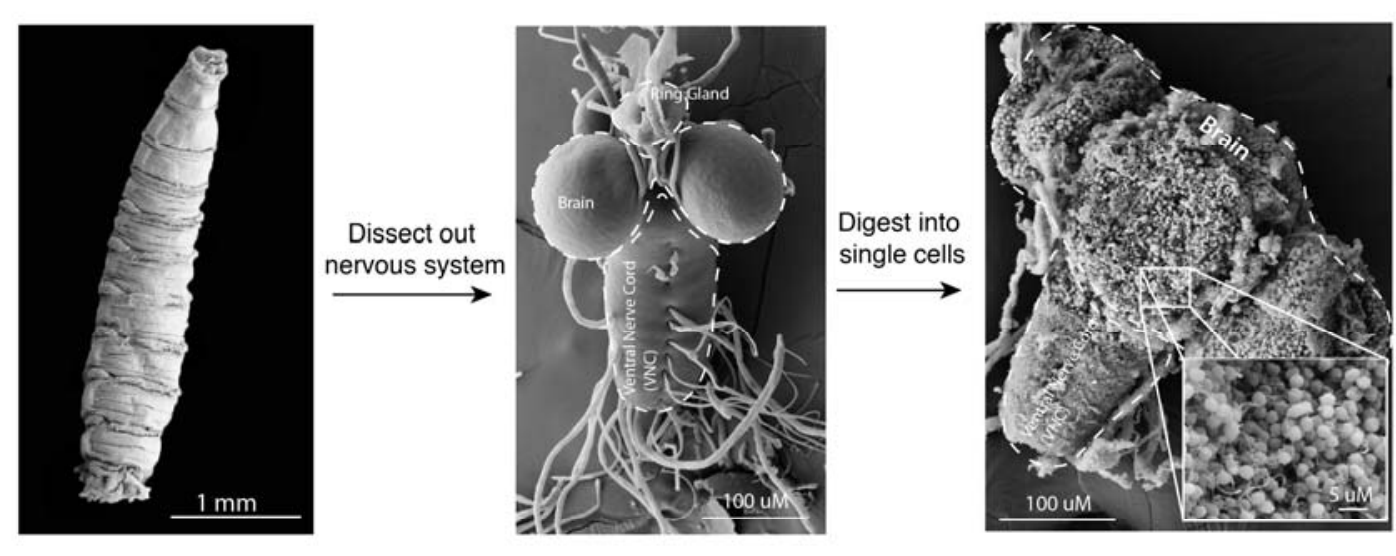

molecular cell type discovery with polyseq
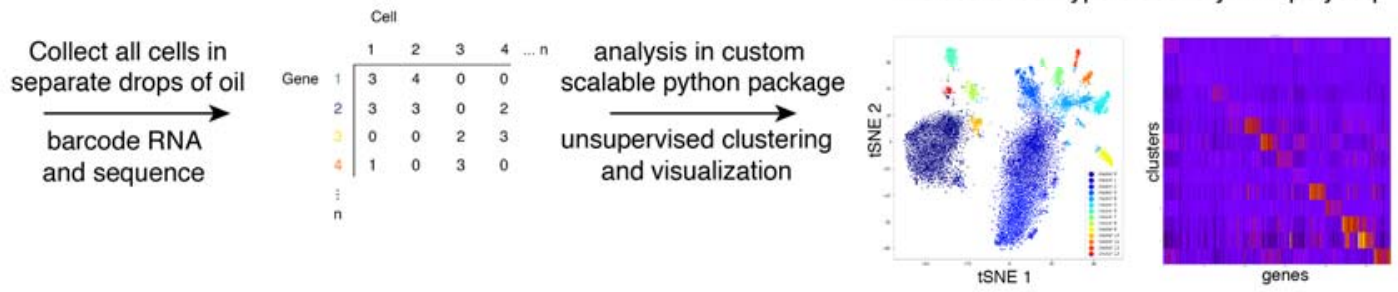

anatomical location of novel cell types $\overrightarrow{\mathrm{RNA}-\mathrm{FISH} \text { and }}$ confocal microscopy

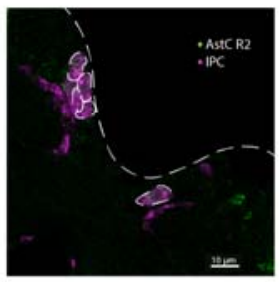

absolute quantification and subcellular RNA location single molecule RNA-FISH and

$$
\underset{\begin{array}{c}
\text { repeated fictive } \\
\text { wasp sting }
\end{array}}{\stackrel{\text { optogenetic activation }}{\text { to alter internal state }}}
$$

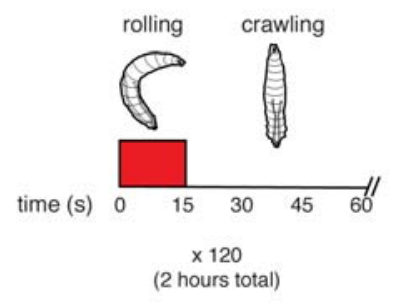

(2 hours total) BB-SIM

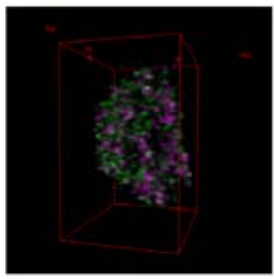

molecular cell state discovery

search for nervous system-wide $\stackrel{\text { cell state changes }}{\longrightarrow}$

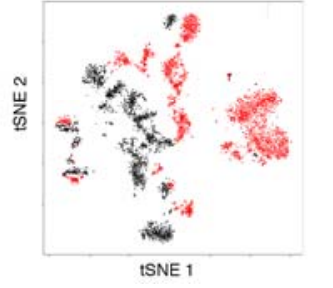

537 Figure 1. Schematic of full nervous system scRNA-seq collection and analysis. In

538 order to develop a central nervous system-wide transcriptomic atlas of the Drosophila

539 nervous system with single-cell resolution, we developed a protocol to digest the entire

540 nervous system into single cells, collected the cells using a microfluidic device (10x

541 Chromium machine, 10x Genomics, Pleasanton, CA), and sequenced the mRNA from

542 each cell. After barcoding and sequencing, a cell by gene matrix is generated. This cell 
543 by gene matrix was then analyzed with polyseq, a custom python package. In total, 544202,107 neurons and glia were sequenced. The anatomical location of newly defined

545 molecular cell types were validated and identified using RNA-FISH with confocal

546 imaging. To push the technique forward, RNA-FISH combined with Bessel beam

547 selective plane illumination microscope (BB-SIM) was used to obtain the absolute

548 quantification and subcellular location of transcripts in these new cell types. Optogenetic

549 manipulations were performed to alter the internal state of the animal, either with two

550 hours of fictive wasp sting or two hours of overactivation of $10 \%$ of brain neurons, and

551 scRNAseq was used once more to search for a change in molecular cell state between

552 conditions. 
bioRxiv preprint doi: https://doi.org/10.1101/785931; this version posted January 16,2020 . The copyright holder for this preprint (which was not certified by peer review) is the author/funder, who has granted bioRxiv a license to display the preprint in perpetuity. It is made available under aCC-BY-NC-ND 4.0 International license.

A

D

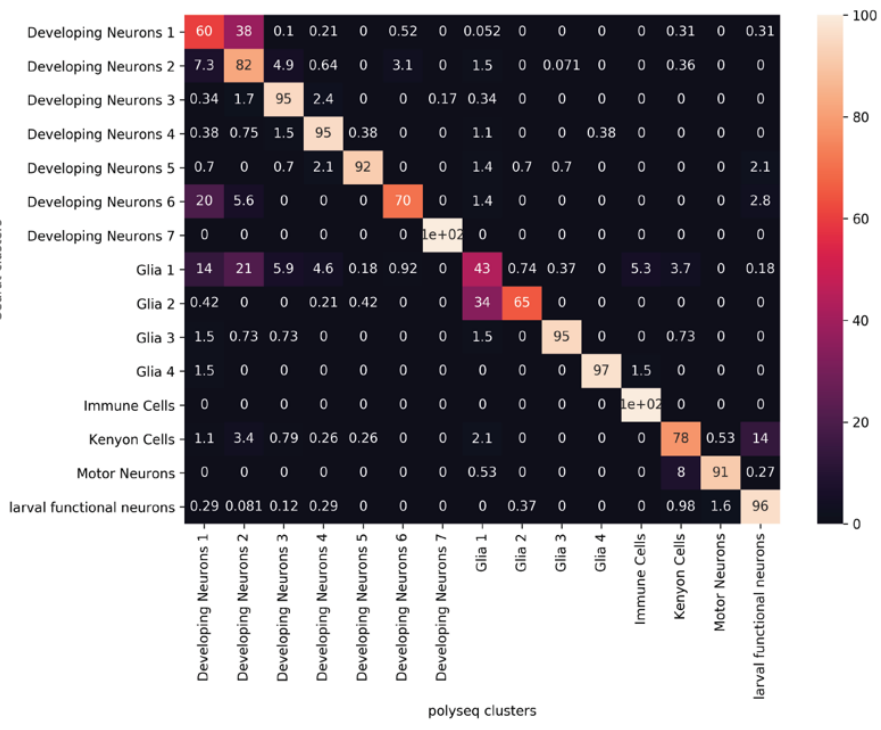

B

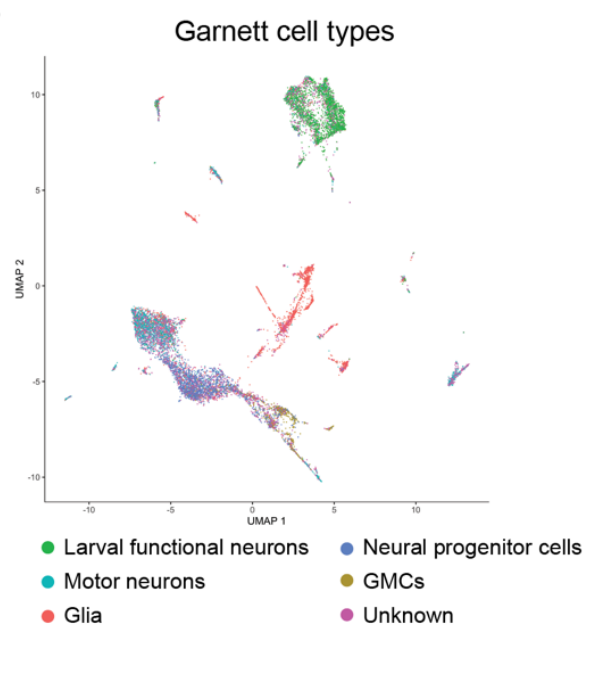

Batch Correction Method Comparison

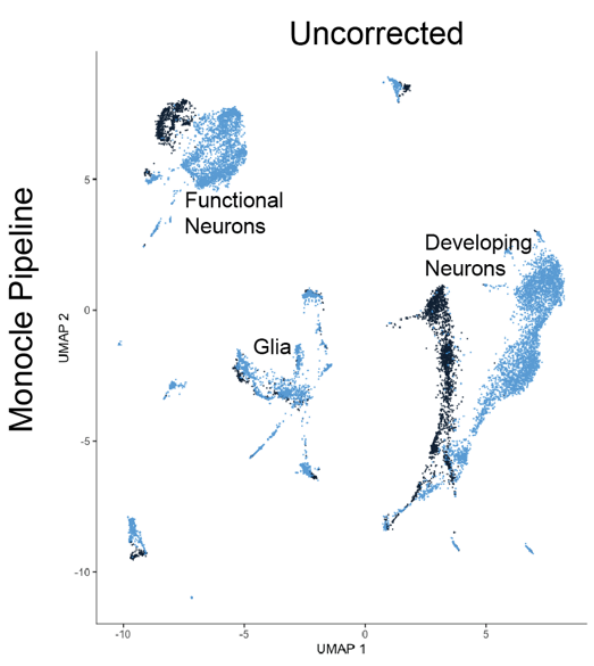

E
Uncorrected

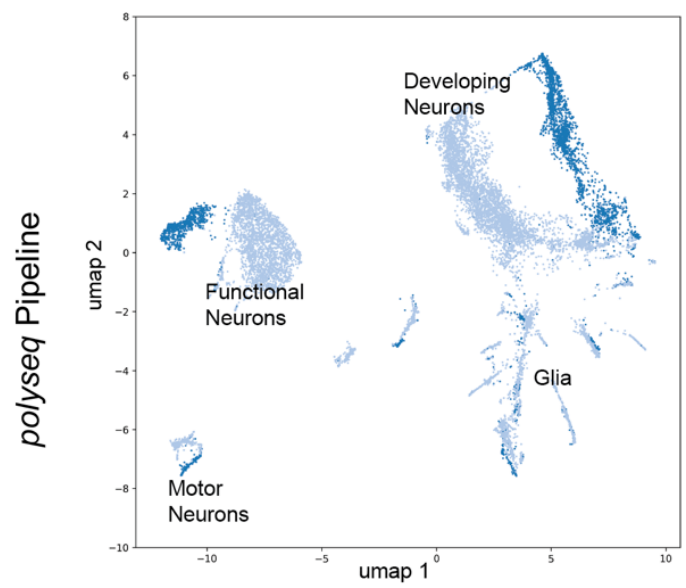

Monocle "align" function

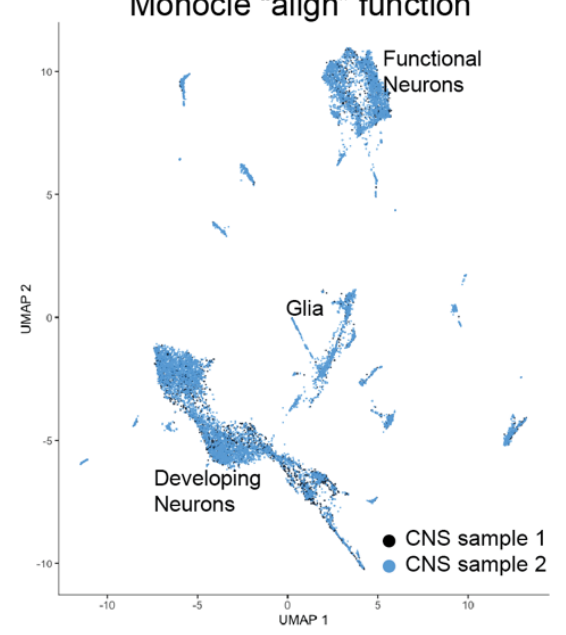

polyseq linear regression

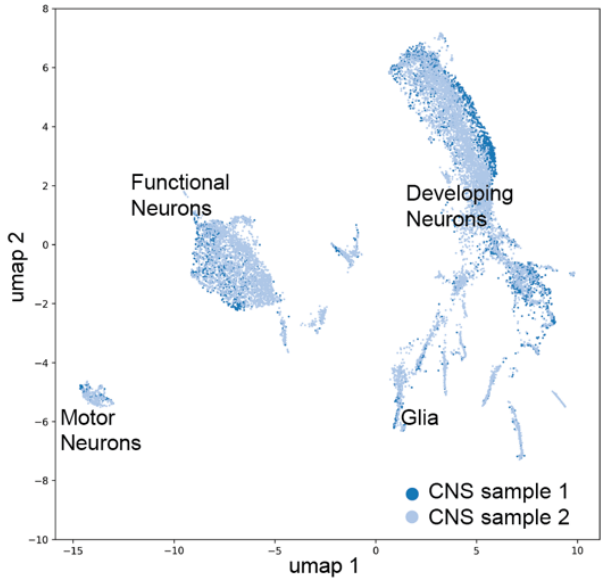




\section{Figure 2. Polyseq python package performs cell type discovery and batch}

557 correction. A. The same dataset was analyzed in polyseq and Seurat. A confusion

558 matrix was generated to compare how cells were clustered together. Fifteen clusters

559 were found in both analyses, with 8 of 15 clusters containing more than $90 \%$ of the

560 same cells. Clusters that disagreed about cell placement were often differing between

561 two similar clusters (i.e. deciding whether a cell belonged to glia 1 vs glia 2). B. Garnett,

562 a newly developed unsupervised technique, was used to label cell groups with known

563 markers (Pliner et al., 2019). This analysis correctly annotated larval functional neurons,

564 motor neurons, glia, NPCs, and GMCs. It also provides an "unknown" label for cells with

565 low confidence. D,E. Batch correction performance was compared in Monocle and

566 polyseq. In the plots, cells are separated by a signature related to small differences in

567 sample collection rather than cell type signatures. Monocle's align function correctly

568 collapses the separated developing neurons (blue and black in "uncorrected" plot) into a

569 comingled group. The linear regression method we implemented in polyseq also

570 collapses the sample separations (such as the separation of motor neurons, functional

571 neurons and developing neurons) in the "uncorrected" plot into a single, mixed group in

572 the umap plot following linear regression. 
bioRxiv preprint doi: https://doi.org/10.1101/785931; this version posted January 16,2020 . The copyright holder for this preprint (which was not certified by peer review) is the author/funder, who has granted bioRxiv a license to display the preprint in perpetuity. It is made available under aCC-BY-NC-ND 4.0 International license.

A

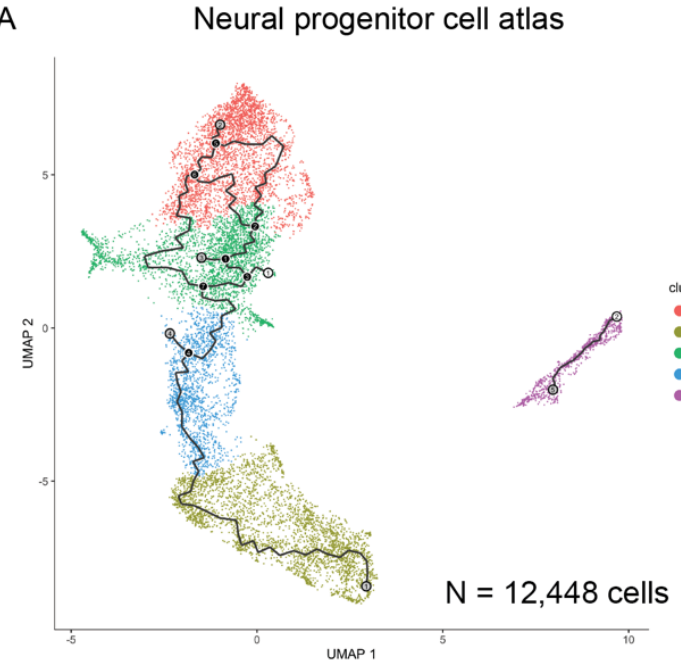

C Neural progenitor cell markers over devleopment

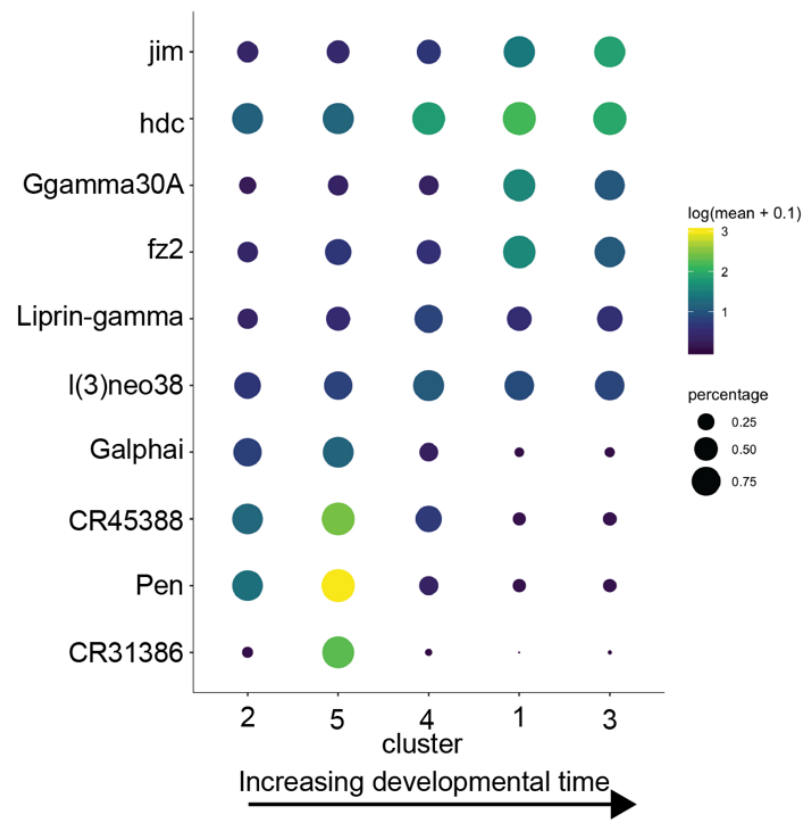

B

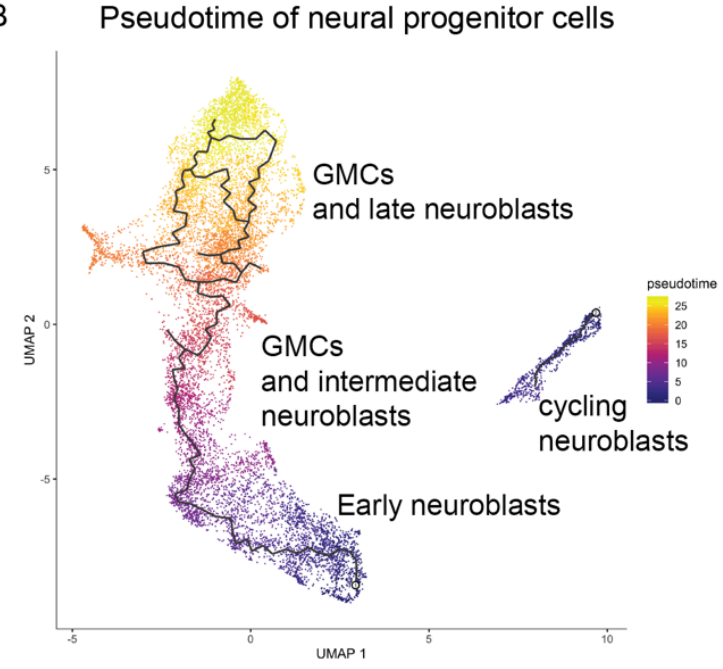

D

Gene modules
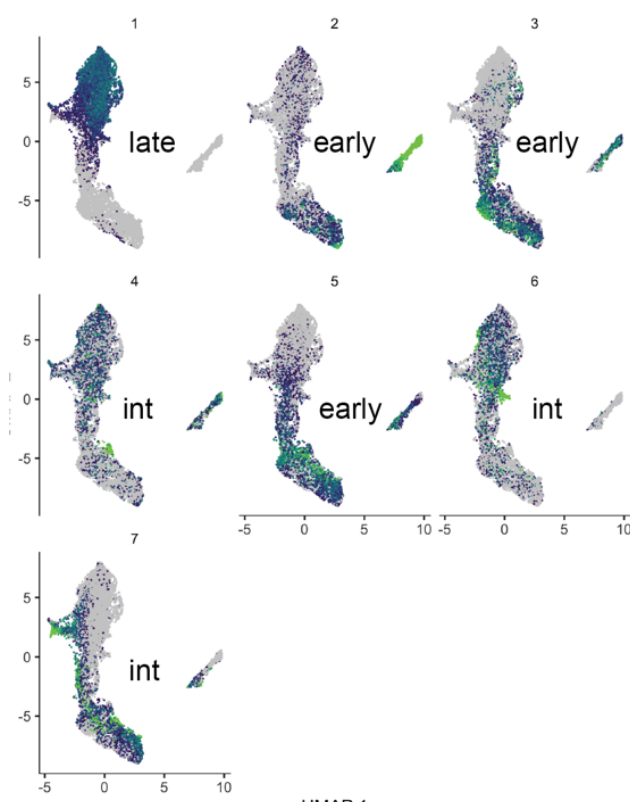

UMAP 1

E Significantly enriched GO Terms in Gene Modules

Early NPCs (Modules 2,3,5)

GO:0000381 regulation of alternative mRNA splicing GO:0006338 chromatin remodeling

GO:0034728 nucleosome orgnization

GO:0055059 asymmetric neuroblast division

GO:0043044 ATP-depedent chromatin remodeling

GO:0006260 DNA replication

GO:0008284 postive regulation of cell proliferation
Intermediate NPCs (Modules 4,6,7)

GO:0006605 protein targeting

GO:0072665 protein localization to vacuole GO:0007034 valcuolar transport

GO:0055085 transmembrane transport

GO:0042135 neurotransmitter catabolic process

GO:0006084 acetyl-CoA metbolic process

GO:0006576 cellular biogenic amine metabolic proces
Late NPCs (Module 1)

GO:0007411 axon guidance

GO:0050808 synapse orginzation

GO:0042391 regulation of membrane potential

GO:0016079 synaptic vesicle exocytosis

GO:0007606 sensory perception of chemical stimulus GO:00072678 chemical synaptic transmission

\section{Terminal neuronal cell type specification}


582 Figure 3. Neural progenitor cell (NPC) atlas reveals gene modules across

583 developmental time. A. A full atlas of first $(1 \mathrm{H})$, second $(24 \mathrm{H})$, and third $(48 \mathrm{H})$ instar

584 larval cells was built, and all NPCs were extracted. These NPCs were then analyzed

585 with Monocle and split into five clusters. B. A pseudotime analysis was performed using

586 known developmental times and separated the data into early, intermediate, and late

587 NPCs. A group of cycling neuroblasts was found to the right of the main NPC dataset in

588 UMAP space. C. Markers for each NPC cluster were extracted and revealed the change

589 in gene expression over developmental time. D. Gene modules were computed and

590 characterized early, intermediate, and late NPCs. As the gene modules represented

591 more developed cells, they were enriched for GO terms (E) which characterized more

592 developed cells (Table S2). 
bioRxiv preprint doi: https://doi.org/10.1101/785931; this version posted January 16,2020 . The copyright holder for this preprint (which was not certified by peer review) is the author/funder, who has granted bioRxiv a license to display the preprint in perpetuity. It is made available under aCC-BY-NC-ND 4.0 International license.

A

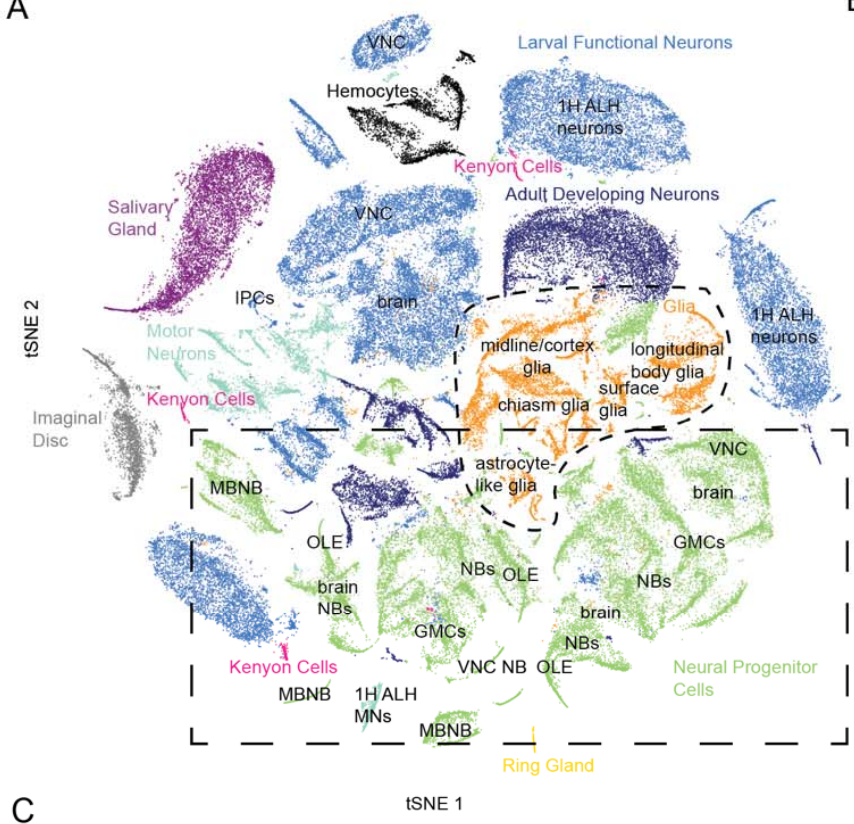

Glia labeled by age

西

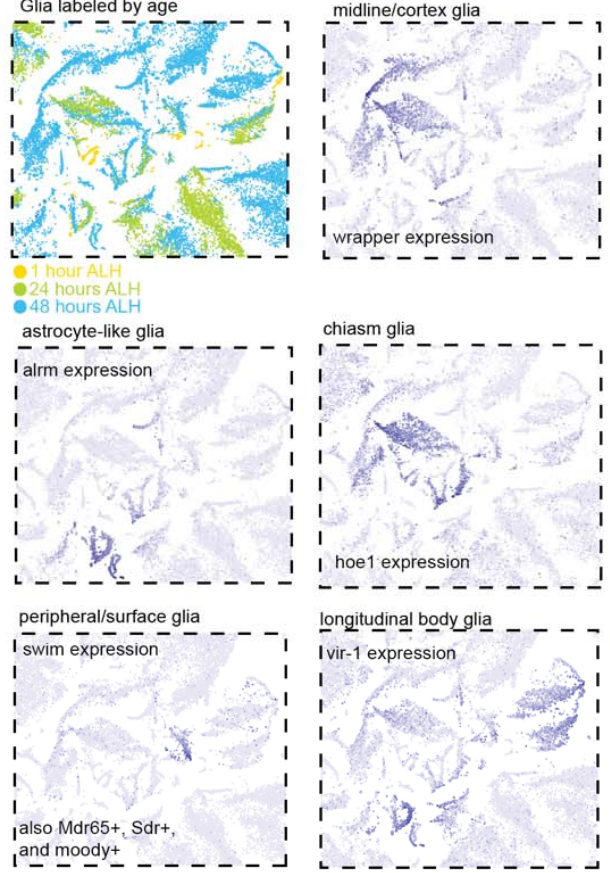

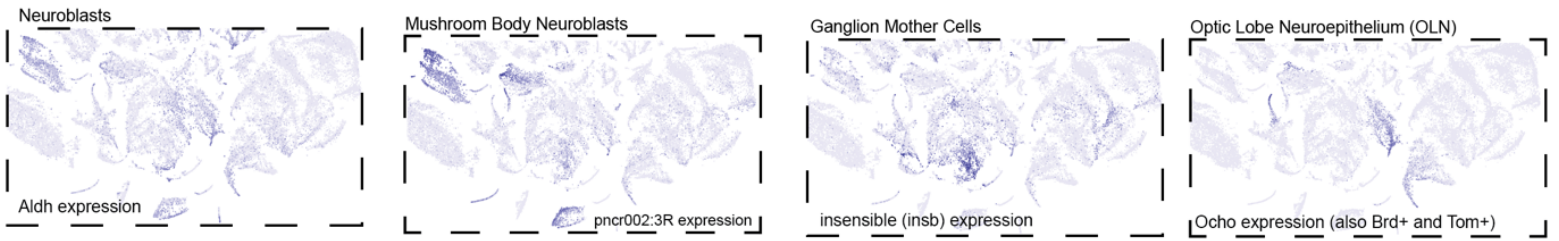

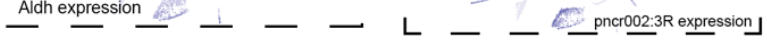

insensible (insb) expression

는 expression (also Brd+ and $\mathrm{Tom}^{+}$) 」

D

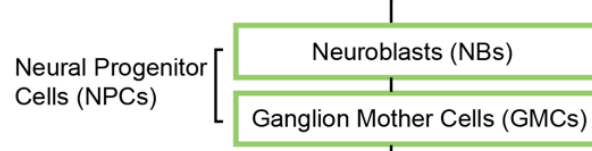

Cell classes found in the full atlas

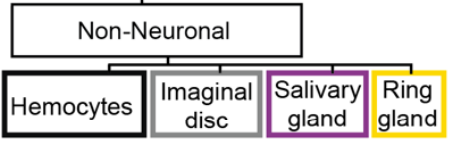

$\mathrm{E}$
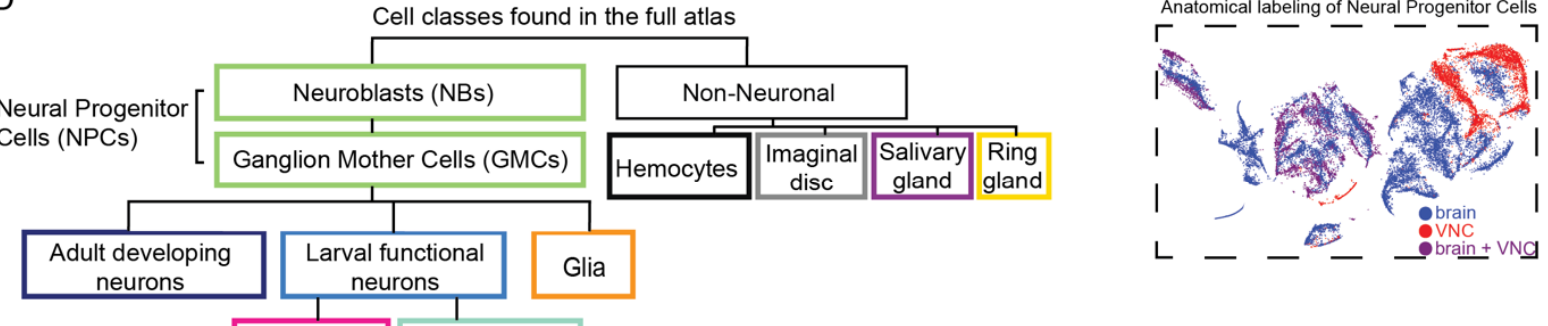

\section{Kenyon cells Motor neurons}

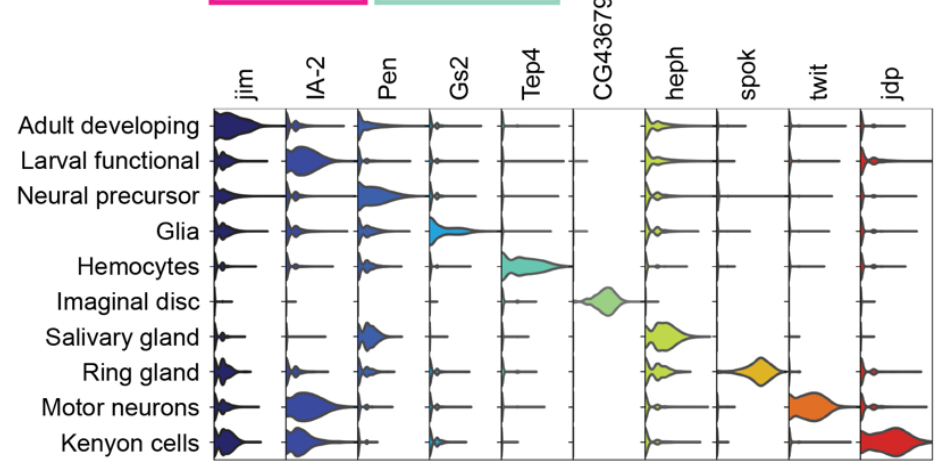

F

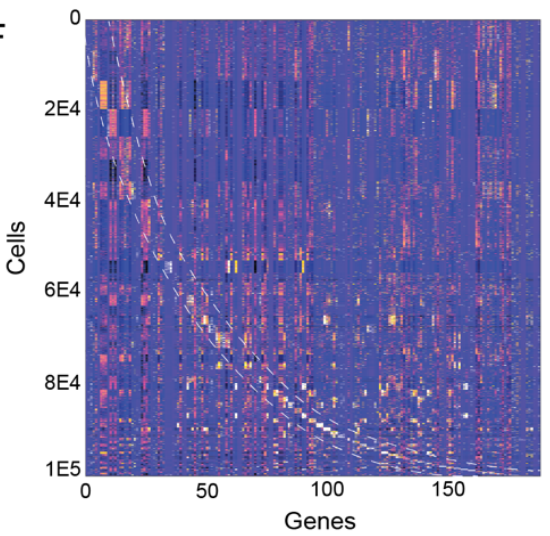


598 Figure 4. Single-cell transcriptomic atlas of the larval central nervous system. A. t-

599 SNE visualization of high-quality cells colored by cell class. Cells broke into 70 clusters

600 (Figure S4; Table S1) and were post-hoc identified as adult developing neurons, larval

601 functional neurons, neural progenitor cells, glia, hemocytes, imaginal disc, salivary

602 gland, ring gland cells, or subsets of these cells, such as motor neurons, Kenyon cells,

603 neuroblasts, or ganglion mother cells (Table S1). B. Five subtypes of glia, labeled in

604 orange, were found comingled in t-SNE space and could be distinguished by age and

605 function. C. Neural progenitor cells, labeled green in the t-SNE space, split into

606 recognizable classes, including neuroblasts, ganglion mother cells, and optic lobe

607 neuroepithelium. D. Diagram of cell classes contained in the atlas (see Figure S1 for

608 more information). E. Genes that define each cell cluster and cell class were

609 discoverable (Table S1). Violin plots show exemplar genes from each cell class. F.

610 Heatmap of all high-quality cells and the top 3 genes that define each cluster. 
A Insulin Producing Cells (IPC) Anatomy

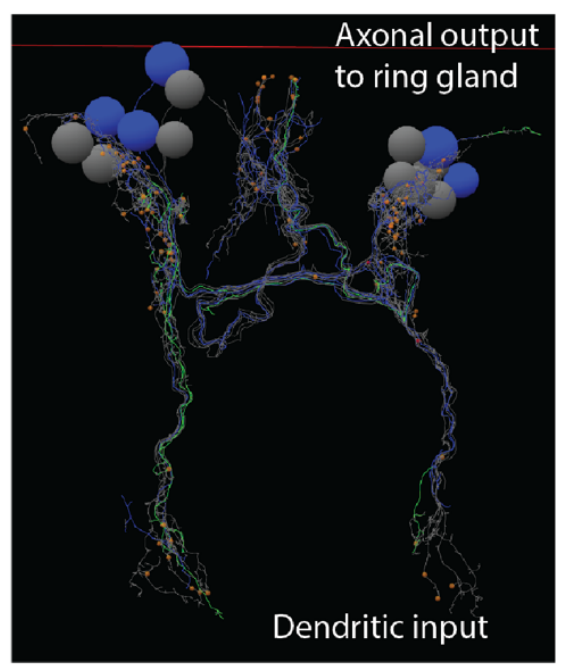

C IPC scRNAseq receptor prediction

615

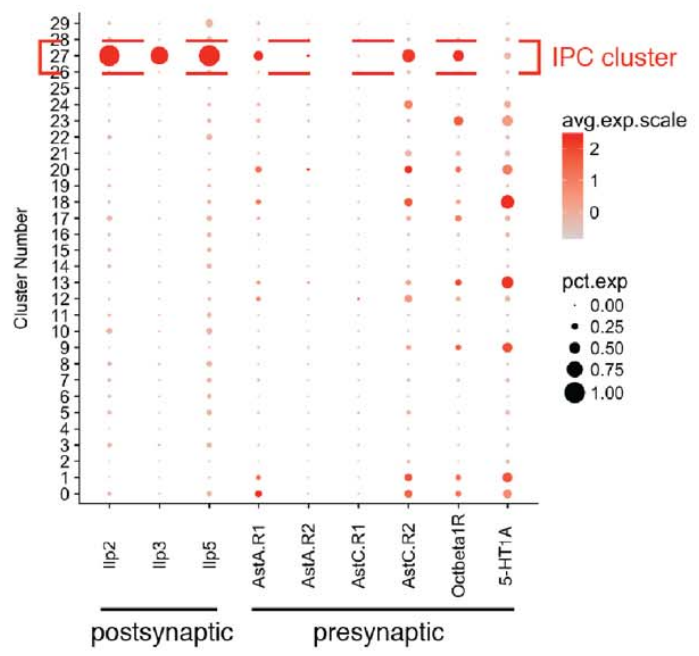

B Insulin-like peptide expression in scRNAseq atlas

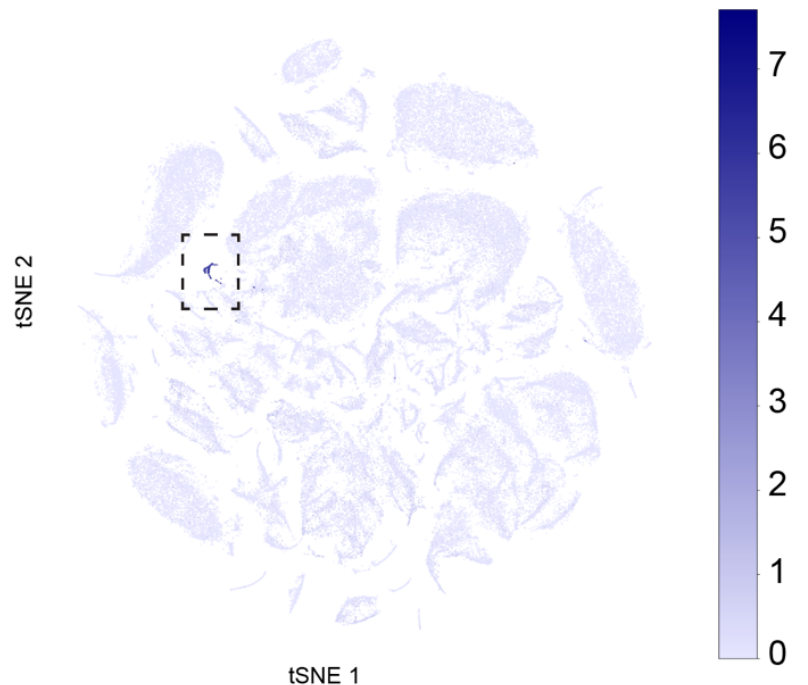

D RNA-FISH validation and localization dilp2-GAL4; UAS-myr-HaloTag

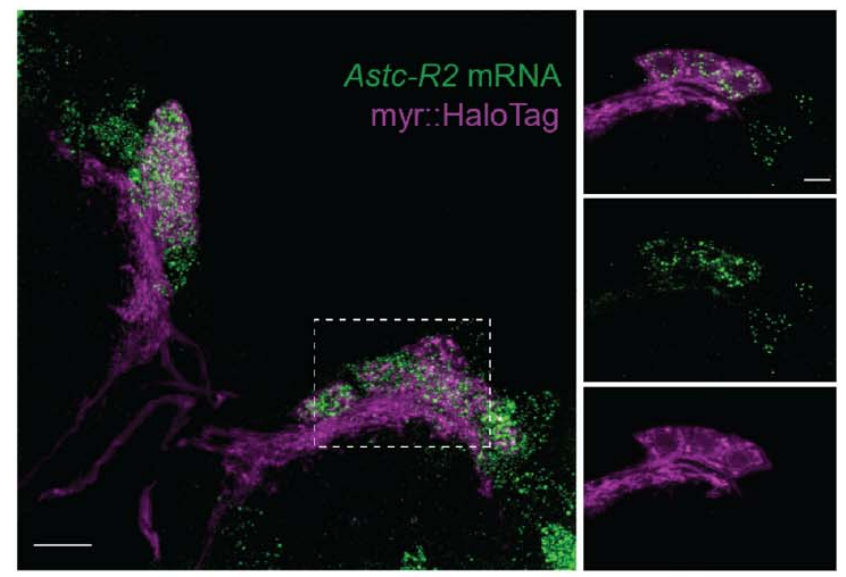

617 Figure 5. Transcriptomic Atlas predicts previously unknown neuropeptide

618 phenotype for insulin-producing cells and is verified by RNA-FISH. A. Anatomy of

619 insulin-producing cells (IPCs). The IPCs are a group of 7 bilaterally symmetrical

620 neurons which receive input through their dendrites (purple) about the nutritional state

621 of the animal and release insulin-like peptides (ILP2, ILP3, ILP5) through their axons

622 (green), which synapse on the ring gland, to control carbohydrate balance. They are

623 analogous to the vertebrate pancreatic beta islet cells. B,C. The RNAseq atlas built in

624 this study discovered the IPCs as a separate cluster (cluster 27 in C) with expression in

625 the IPCs of receptors for octopamine, serotonin, and allatostatin A, which matched 
626 previous literature. Surprisingly, the atlas also suggested the presence of a previously

627 unrecognized receptor in the IPCs for allatostatin C (AstC-R2). D. Detection of AstC-R2

628 mRNA in IPCs. Maximum-intensity projection of the confocal stack of a brain in which

629 the IPCs are labeled with a fluorescent HaloTag ligand (Magenta) and AstC-R2 mRNA

630 is detected by FISH (green), bar $10 \mu \mathrm{m}$. Dashed lines outline area where the single z

631 plane is shown on the left panels, bar $5 \mu \mathrm{m}$. Movie of $D$ is in the supplement (Movie S1).

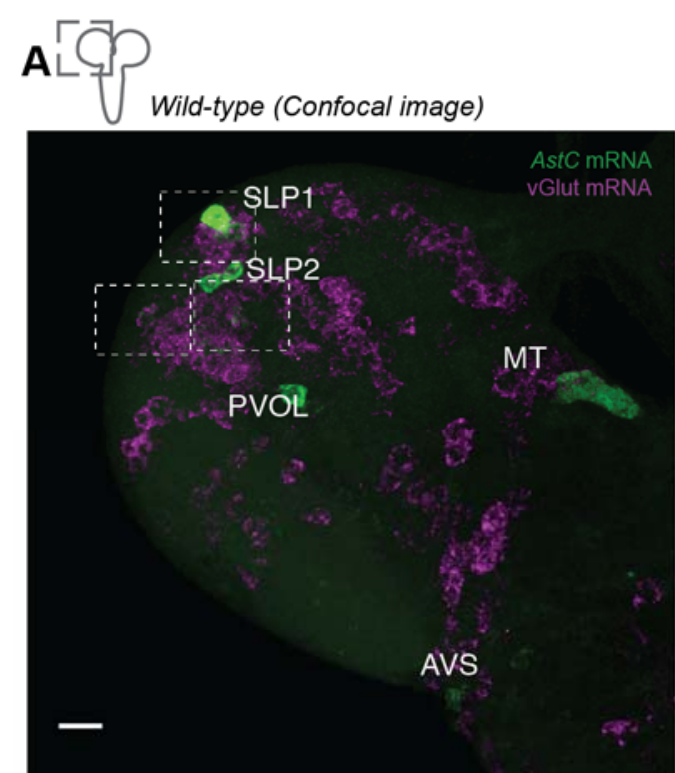

B Wild-type (BB-SIM image)
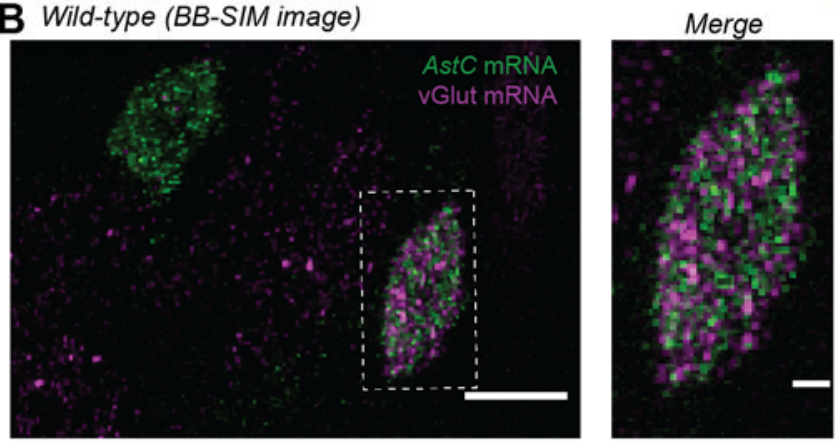

vGlut mRNA

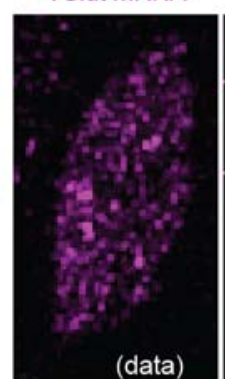

634

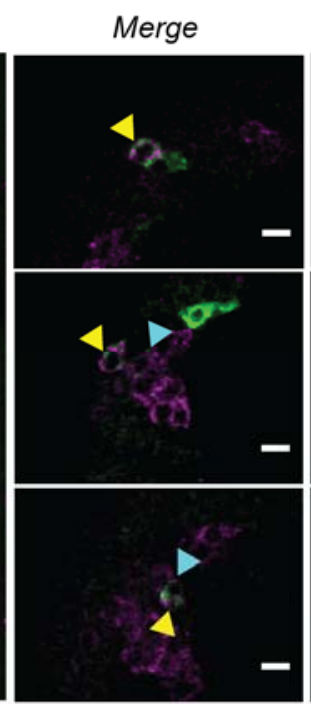

vGlut mRNA

AstC mRNA
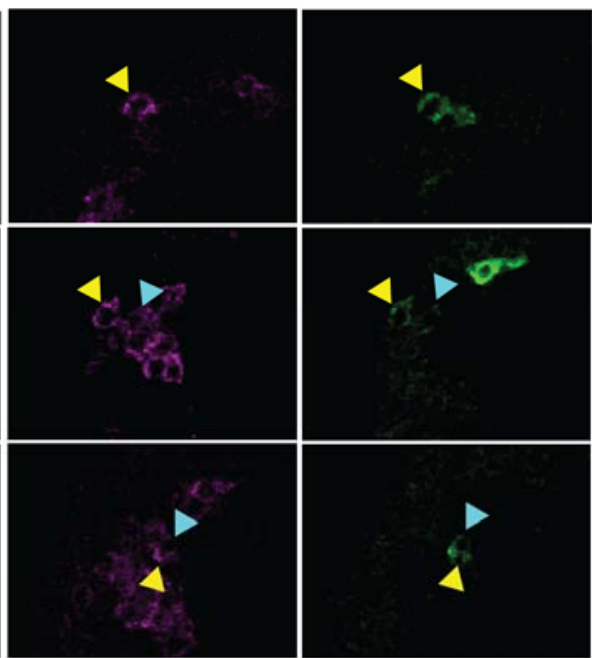

C
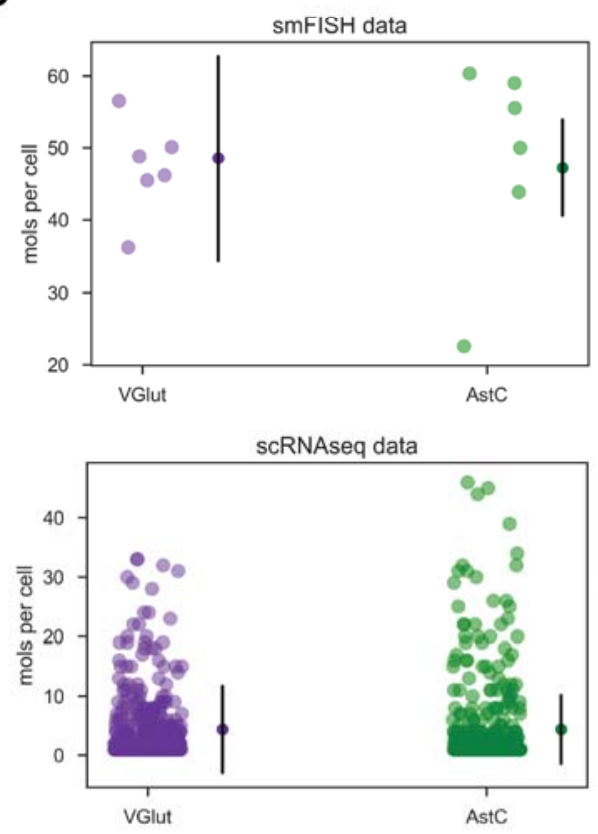
636 Figure 6. Correlation between single-molecule FISH and scRNAseq. A. Identifying

637 cells that have coexpression of AstC (green) and vGlut (magenta) in the whole brain B.

638 Maximum-intensity projections of BB-SIM stack of the AstC and vGlut mRNA FISH

639 channels, bar $10 \mu \mathrm{m}$. Dashed lines outline 2 cells that co-express AstC and vGlut

640 mRNAs are shown on the right panels, bar $1 \mu \mathrm{m}$. Lower panels show individual FISH

641 channel and the reconstructions obtained using the spot-counting algorithm. C.

642 Comparison of the quantification of AstC and vGlut mRNAs between smFISH and

643 scRNAseq.

644 
bioRxiv preprint doi: https://doi.org/101101/785931; this version posted January 16,2020 . The copyright holder for this preprint (which was not certified by peer review) is the author/funder, who has granted bioRxiv a license to display the preprint in perpetuity. It is made available under aCC-BY-NC-ND 4.0 International license.

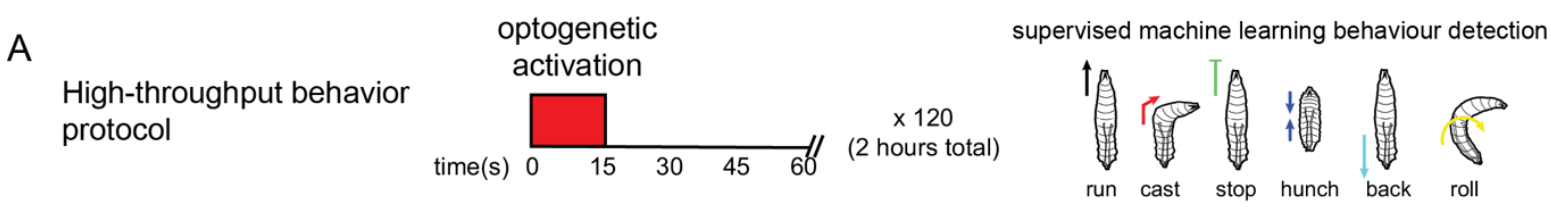

B Optogenetic sting

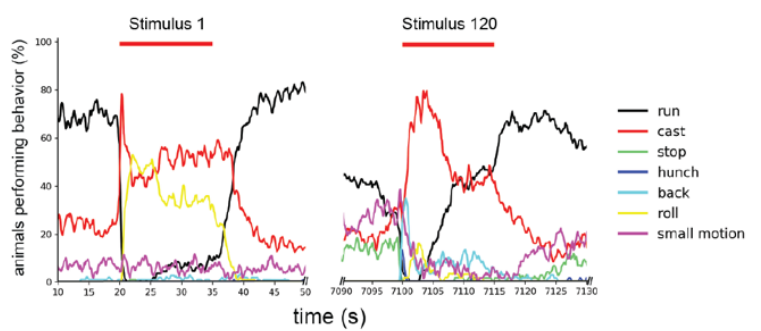

D Will cells cluster based on cell type or cell state signature?

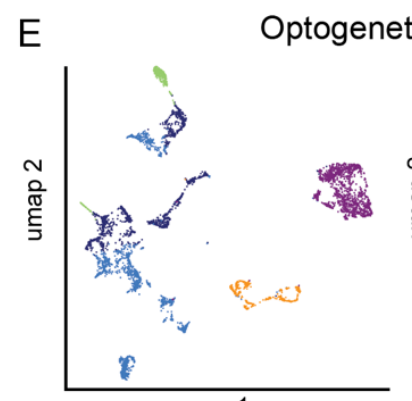

umap 1

cell state clustering
Molecular Cell Type

adult dev neurons neuroblasts

larval neurons glia

G

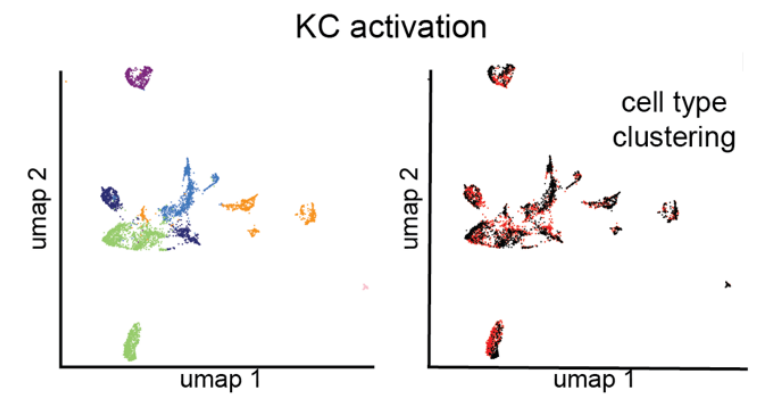

\begin{tabular}{|lll|}
\hline Molecular Cell Type & Molecular Cell State \\
$\begin{array}{l}\text { adult dev neurons } \\
\text { larval neurons }\end{array}$ glia & immune cells & KC activation \\
\hline
\end{tabular}

645 cell type clustering cell state clustering

$\mathrm{F}$

C Optogenetic Kenyon Cell activation

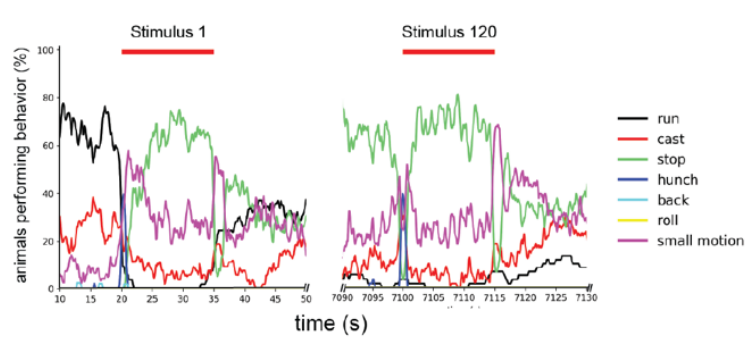

F Cell state genes across all cell populations

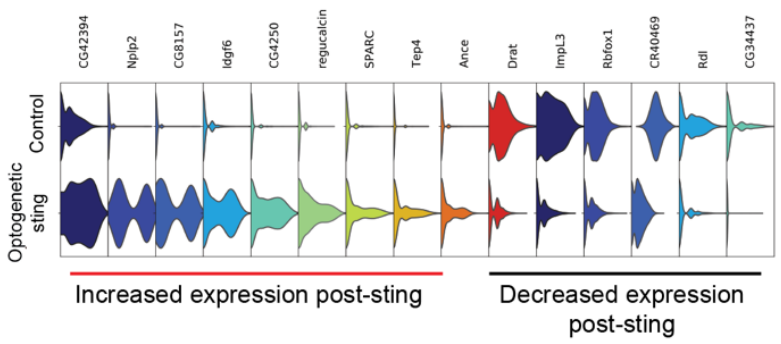

$\mathrm{H}$ Cell state genes within Kenyon Cells

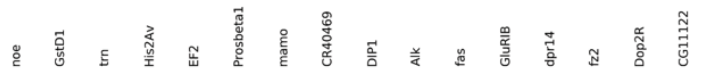

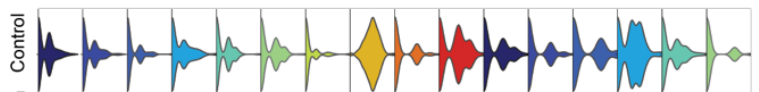

竞

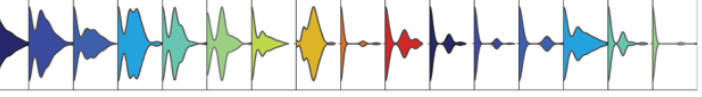

Increased expression in Increased expression in activated $\mathrm{KCs}$ control KCs

I Cell state genes within Dopaminergic Neurons
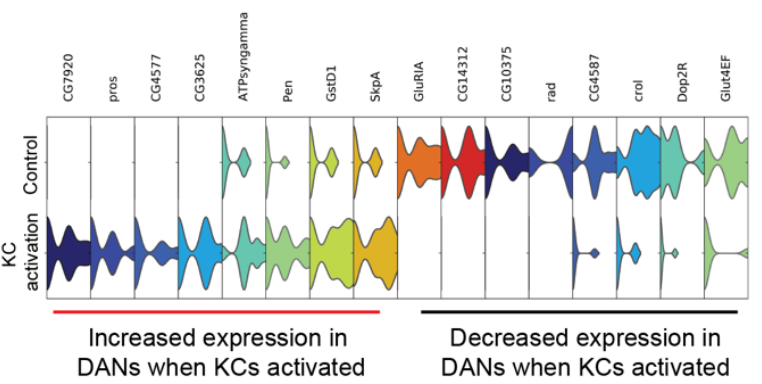
646 Figure 7. Optogenetic sting and $\mathrm{KC}$ activation induce a change in internal state, 647 which is observable as cell state changes in gene expression. A. High-throughput

648 behavior assays were performed using previously described equipment (Ohyama et al.,

649 2013). Fifteen seconds of optogenetic activation were delivered every 60 seconds over

650 a two-hour period. Larval behavior was recorded and supervised machine learning

651 techniques were used to classify behavior as one of six behaviors. B. For the

652 optogenetic sting protocol, animals first respond to basin activation by performing an

653 escape response, including a fast turning response and rolling as previously described

654 (Hwang et al., 2007; Ohyama et al., 2013; Ohyama et al., 2015). Over the course of the

655 experiment, a switch in behavior is observed from rolling to backing up. C. Kenyon cell

656 activation led to a hunch followed by freezing. At the start of training, animals crawled

657 forward to offset. After training, the hunch and freezing response remained at the onset,

658 but the offset response switched to a turn rather than a forward crawl. D. Transcriptomic

659 atlases were produced from animals that underwent each behavior protocol and

660 matched controls. We were primarily interested in whether cell state or cell type

661 clustering would be observed after altering internal state (sting) or overactivating the

662 memory center (KC activation). Cell type clustering would result in cells from activated

663 animals and controls mixing in the same clusters while cell state clustering would lead

664 to separation of cells from activated and control animals. E,F. The optogenetic sting

665 protocol led to cell state clustering. All cell classes were identifiable for both conditions.

666 A large immune cell population was specific to the sting condition, suggesting an

667 immune response to a fictive wasp sting (Figure S8). F. Cell state genes were

668 discovered with upregulated and downregulated expression that separated all cell

669 populations. G-I. KC activation led to cell type clustering and local cell state changes.

670 Even though a larger total number of cells were activated ( 200 KCs versus 64 basins),

671 a less dramatic switch was observed in behavior and in the transcriptome. There were

672 differentially expressed genes in two key populations of cells in the learning and

673 memory center: KCs and dopaminergic neurons.

674

675

676 


\section{METHODS:}

\section{CONTACT FOR REAGENT AND RESOURCE SHARING}

679 Further information and requests for resources and reagents should be directed to and 680 will be fulfilled by the Lead Contact, Marta Zlatic (zlaticm@janelia.hhmi.org).

\section{EXPERIMENTAL MODEL AND SUBJECT DETAILS}

\section{Fly stocks}

684 Drosophila larvae were grown on standard fly food at $25^{\circ} \mathrm{C}$ and kept in 12 -hour 685 day/night light and dark cycle. Vials were timed by collecting eggs on a new food plate 686 over the course of one hour. Please see Key Resources Table for Drosophila lines used in this study.

\section{METHOD DETAILS}

\section{Single cell isolation}

692 Drosophila larvae were dissected at 1 hour, 24 hours, 48 hours, or 96 hours after larval

693 hatching (ALH). All dissections were performed in a cold adult hemolymph solution

694 (AHS) with no calcium or magnesium at pH 7.4. Quality of single cell isolation was

695 investigated by visual inspection with compound and confocal microscopy. Samples

696 were placed on ice during waiting periods. Samples were isolated and run on the 10x

697 Chromium Single Cell 3' immediately after cell dissociation.

699 First, the complete central nervous system (CNS) was dissected from every animal. The 700 dissected nervous systems were kept in cold AHS on ice. For those samples where the 701 brain and the ventral nerve cord (VNC) were sequenced separately, the separation of 702 the brain from the VNC was performed using fine-tipped forceps and MicroTools (Cat \#:

703 50-905-3315, Electron Microscopy Sciences). The time from digestion (the part of the 704 protocol most likely to induce cell stress) to on the 10x Genomic instrument was never 705 longer than 30 minutes. 
707 After separation of the brain from the VNC, the desired tissue was placed in $18 \mu \mathrm{L}$ of

708 AHS on ice. Once all samples were prepared, $2 \mu \mathrm{L}$ of $10 x$ neutral protease (Cat \#:

709 LS02100, Worthington Biochemical Corp, Lakewood, NJ, USA) was added to a final

710 volume of $20 \mu \mathrm{L}$. The intact brain tissue was digested for 5 minutes. The tissue was

711 then transferred to a fresh drop of $20 \mu \mathrm{L}$ of $\mathrm{AHS}$.

713 Each sample was triturated with a clean, thinly pulled glass electrode until no tissue was

714 visible under a dissection scope. All debris (pieces of nerve and undigested neuropile)

715 was removed. Samples with fluorescent markers were observed under a fluorescence

716 microscope to approximate cell density. The samples were then loaded onto the 10x

717 Chromium chip.

\section{X Genomics}

720 Single cell capture and library construction was performed using the 10x Chromium

721 machine and the Chromium Single Cell 3' v2 Library and Gel Bead Kit (10x Genomics,

722 Pleasanton, CA). Manufacturer's recommendations were followed for cell collection and

723 library construction. Libraries were sequenced with an Illumina HiSeq following

724 manufacturer's instructions.

\section{6 mRNA in situ hybridization}

727 FISH probes were designed based on transcript sequences using the online Stellaris

728 Designer and purchased from Biosearch Technologies. Probe sequences for AstC and

729 vGlut were previously reported (Long et al,. 2017; Diaz et al., 2019), and probe

730 sequences for AstC-R2, Hug, NPNL2 are in Table S5. Each probe is 18-22nt long with a

731 3' end amine-modified nucleotide that allows directly couple to an NHS-ester dye

732 according to the manufacturer's instructions (Life Technologies). Dye-labeled probes

733 were separated from the excess free dyes using the Qiagen Nucleotide Removal

734 Columns. FISH protocol was described previously (Long et al,. 2017; Diaz et al., 2019).

735 The brains of 3rd instar larvae were dissected in 1xPBS and fixed in $2 \%$

736 paraformaldehyde diluted PBS at room temperature for $55 \mathrm{~min}$. Brain tissues were

737 washed in $0.5 \%$ PBT, dehydrated, and stored in $100 \%$ ethanol at $4^{\circ} \mathrm{C}$. After exposure to 
$7385 \%$ acetic acid at $4{ }^{\circ} \mathrm{C}$ for 5 minutes, the tissues were fixed in $2 \%$ paraformaldehyde in

$7391 \times$ PBS for 55 min at $25^{\circ} \mathrm{C}$. The tissues were then washed in $1 \times$ PBS with $1 \%$ of $\mathrm{NaBH} 4$

740 at $4{ }^{\circ} \mathrm{C}$ for $30 \mathrm{~min}$. Following a 2 hour incubation in prehybridization buffer (15\%

741 formamide, $2 \times \mathrm{SSC}, 0.1 \%$ Triton $\mathrm{X}-100)$ at $50{ }^{\circ} \mathrm{C}$, the brains were introduced to

742 hybridization buffer (10\% formamide, $2 \times$ SSC, $5 \times$ Denhardt's solution, $1 \mathrm{mg} / \mathrm{ml}$ yeast

743 tRNA, $100 \mu \mathrm{g} / \mathrm{ml}$, salmon sperm DNA, 0.1\% SDS) containing FISH probes at $50{ }^{\circ} \mathrm{C}$ for

$74410 \mathrm{~h}$ and then at $37^{\circ} \mathrm{C}$ for an additional $10 \mathrm{~h}$. After a series of wash steps, the brains

745 were dehydrated and cleared in xylenes.

747 Confocal and BB-SIM Imaging

748 For confocal imaging, the tissues were mounted in DPX. Image Z-stacks were collected

749 using an LSM880 confocal microscope fitted with an LD LCI Plan-Apochromat 25x/0.8

750 oil or Plan-Apochromat 63x/1.4 oil objective after the tissue cured for 24 hours. For

751 single-molecule imaging, we use a previous described Bessel beam selective plane

752 illumination microscope (BB-SIM). Detail construction of microscope and the imaging

753 procedure is described previously (Long et al., 2017). Briefly, this BB-SIM is engineered

754 to image in medium matched to the measured refractive index (RI) of xylene-cleared

755 Drosophila tissue with axial resolution of $0.3 \mu \mathrm{m}$ and lateral resolution of $0.2 \mu \mathrm{m}$. For

756 BB-SIM imaging, the tissues were mounted on a 1.5x3mm poly-lysine coated coverslip

757 attached to a $30 \mathrm{~mm}$ glass rod. The imaging process requires the objectives and tissues

758 immersed in the imaging medium consist with 90\% 1,2-dichlorobenzene, 10\% 1,2,4-

759 trichlorobenzene with refractive index $=1.5525$. Two orthogonally mounted excitation

760 objectives are used to form Bessel beams, which are stepped to create an illumination

761 sheet periodically striped along $\mathrm{x}$ or $\mathrm{y}$, while a third objective (optical axis along the $\mathrm{z}$

762 direction) detects fluorescence. To employ structured illumination analysis, we collect

763 multiple images with the illumination stripe pattern shifted to tile the plane in $x$, and

764 repeat the process orthogonally to tile the plane in y. The sample is then moved in z,

765 and the imaging repeated, and so on to image the 3D volume.

767 High-throughput Automated Optogenetic Behavior Experiments 
768 For the sting mimic experiments, 72F11-GAL4 males were crossed to UAS-CsChrimson

769 virgins (stock information in Key Resources Table). For Kenyon cell overactivation,

770 201Y-GAL4 males were crossed to UAS-CsChrimson virgins. Larvae were grown in the

771 dark at $25^{\circ} \mathrm{C}$. They were raised on standard fly food containing trans-retinal (SIGMA

$772 \mathrm{R} 2500)$ at a final concentration of $500 \mu \mathrm{M}$. Activation was performed in a high-

773 throughput optogenetic behavior rig described previously (Ohyama et al., 2013). About

77440 animals were placed in a $25 \times 25 \mathrm{~cm}^{2}$ dish covered with clear $4 \%$ agar.

776 Neurons were activated using a red LED at $325 \mu \mathrm{W} / \mathrm{cm}^{2}$ illuminated from below the agar

777 dish for 15 seconds with with a 45 second rest period for a total of 120 activation

778 periods (Figure 7A). Supervised machine learning was used to automatically detect

779 behavior (Jovanic et al., 2017). Control animals of the same age were collected from the

780 same food plate as experimental animals and placed on an agar plate in the dark for

781 two hours. Immediately following the sting protocol, 2-4 animals from each group were

782 dissected and cells were collected using the 10X Genomics protocol described above.

\section{QUANTIFICATION AND STATISTICAL ANALYSIS}

\section{4 scRNA-seq analysis}

785 Bioinformatic analysis was performed using Cell Ranger software (Version 1.3.1, 10x

786 Genomics, Pleasanton, CA, USA), the Seurat R package (Satija et al., 2015) and

787 custom software in $\mathrm{R}$ and Python, including the polyseq Python package developed

788 here. Software to train classifiers using neural networks was built with TensorFlow. The

789 polyseq package as well as jupyter notebooks containing code used for analysis in the

790 study are available on GitHub (https://github.com/jwittenbach/polyseq).

792 Briefly, Cell Ranger was used to perform demultiplexing, alignment, filtering, and

793 counting of barcodes and UMIs, with the output being a cell-by-genes matrix of counts.

794 To further ensure that only high-quality cells were retained, any cell that registered

795 counts in a unique number of genes below a baseline threshold was removed. To

796 reduce the dimensionality of the data for computational tractability, any gene that was

797 not expressed in a baseline number of cells was also dropped. 
799 To account for the fact that raw counts tended to span many orders of magnitude (

$80010^{0}-10^{5}$ ), counts were transformed via log(counts +1$)$. To control for cell size and

801 sequencing depth, the sum of the (log-transformed) counts within each cell used as a

802 regressor for a linear regression model to predict the (log-transformed) counts for each

803 gene (one linear regression model per gene, with each cell being a sample). "Gene

804 expression levels" were then quantified as the z-scored residuals from the fitted models

805 (i.e. standard deviations above/below the predicted log-transformed counts for a

806 particular gene across all cells).

808 Next, to further reduce the dimensionality of the data in preparation for downstream

809 clustering and embedding operations (both of which have computational costs that

810 scale poorly with the dimensionality of the feature space), principal component analysis

811 was performed with cells as samples and gene expression levels as features. The top $\mathrm{K}$

812 principal components (PCs) were retained as features for downstream analyses. For the

813 lager cell atlas dataset, $\mathrm{K}$ was chosen to retain a desired percentage of the total

814 variance. For the smaller cell state datasets, $\mathrm{K}$ was chosen automatically via a shuffle

815 test - on each shuffle, gene expression levels for each gene were randomly permuted

816 across all cells and the percent variance explained by the top PC was recorded; the $95^{\text {th }}$

817 percentile of this value across all shuffles was then used as a threshold to determine the

818 cutoff point for keeping PCs with respect to percent variance explained by a particular

819 PC.

821 Based on these top PCs, cells were clustered using the Louvain-Jaccard graph-based

822 clustering approach. Briefly, the k-nearest neighbor graph between cells was is

823 computed. Edge weights are then determined using the Jaccard index, which measures

824 the fraction of shared neighbors between any two nodes. Finally, the Louvain

825 community detection algorithm is applied to this graph to partition the nodes into

826 clusters; this algorithm seeks to optimize weight of connections with each cluster

827 relative to those between clusters. 
829 In order to visualize the results of the analysis, the PC features were also used to

830 perform a nonlinear embedding into two dimensions. This was performed via either the

831 t-SNE or the UMAP algorithm.

833 Once cluster identities were determined, the original gene expression level data was to

834 determine important genes for defining each cluster. For each cluster, gene expression

835 levels were used as features, and a binary indicator of whether or not a cell came from

836 the cluster in question was used as a target. This data was then used to fit a linear

837 classifier (viz, a support vector classifier) to separate in-cluster cells from the rest of the

838 population. The unit normal vector from the linear classifier was then extracted and the

839 components used to rank order genes in terms of importance for defining that cluster.

840 This same technique was also used to find important genes for groups defined by

841 methods other than clustering.

\section{Imaging analysis}

844 To quantify the number of vGlut and AstC mRNAs in cells contain both vGlut and AstC, 845 we first manually segmented cells from BB-SIM z-stacks that have both vGlut and AstC 846 FISH signals using the Fiji plugin TrakEM2 (Schindelin et al., 2012; Meissner et al.,

847 2019). After identifying the individual fluorescent spots in segmented cells used a 848 previously described Matlab algorithm (Lionnet et al., 2011), we calculate the number of 849 mRNAs per cell. Reconstructed images were generated using Matlab code that draws 850 spots centered on each of the detected spots positions (Lionnet et al., 2011).

\section{DATA AND CODE AVAILABILITY}

853 All code and documentation for polyseq is open source and freely available on github 854 (https://github.com/jwittenbach/polyseq). Jupyter notebooks used for analysis are 855 available upon request. The scRNA-seq data has been deposited in GEO and is 856 accessible under the accession code GEO: GSE135810. 


\begin{tabular}{|c|c|c|}
\hline REAGENT or RESOURCE & SOURCE & IDENTIFIER \\
\hline \multicolumn{3}{|l|}{ Critical Commercial Assays } \\
\hline RNA-FISH probes & $\begin{array}{l}\text { Biosearch } \\
\text { Technologies }\end{array}$ & $\mathrm{N} / \mathrm{A}$ \\
\hline RNase-free 1x PBS & Fisher Scientific & BP2438-4 \\
\hline Acetic Acid, Glacial (Certified ACS), Fisher Chemical & Fisher Scientific & A38S-500 \\
\hline Sodium borohydride, $99 \%$, VenPure ${ }^{\mathrm{TM}} \mathrm{SF}$ powder & Acros Organics & AC448481000 \\
\hline SSC (20X) & Fisher & AM9763 \\
\hline $\mathrm{Hi}-\mathrm{Di}$ formamide & Applied Biosystems & 4311320 \\
\hline Denhardt's solution (50X) & Alfa Aesar & AAJ63135AD \\
\hline tRNA from baker's yeast & Roche & 10109495001 \\
\hline UltraPure ${ }^{\mathrm{TM}}$ Salmon Sperm DNA Solution & Fisher Scientific & 15632011 \\
\hline SDS, $10 \%$ & Corning & $46-040-\mathrm{Cl}$ \\
\hline Deionizedformamide & Ambion & AM9342 \\
\hline Chromium Single Cell 30 Library \& Gel Bead Kit v2 & 10x Genomics & PN-120237 \\
\hline Chromium Single Cell A Chip Kit & 10x Genomics & PN-120236 \\
\hline Chromium i7 Multiplex Kit & 10x Genomics & PN-120262 \\
\hline \multicolumn{3}{|l|}{ Deposited Data } \\
\hline Raw and analyzed scRNAseq data & This paper & GEO: GSE135810 \\
\hline \multicolumn{3}{|l|}{ Experimental Models: Organisms/Strains } \\
\hline $\begin{array}{l}\text { D. melanogaster: } \mathrm{w}[1118] ; \mathrm{P}\{\mathrm{y}[+\mathrm{t} 7.7] \\
\mathrm{w}[+\mathrm{mC}]=\mathrm{GMR} 57 \mathrm{C} 10-\mathrm{GAL} 4\} \mathrm{attP} 2\end{array}$ & $\begin{array}{l}\text { Bloomington } \\
\text { Drosophila Stock } \\
\text { Center }\end{array}$ & RRID:BDSC_39171 \\
\hline $\begin{array}{l}\text { D. melanogaster: pJFRC29-10XUAS-IVS-myr::GFP-p10 } \\
\text { in attP40; pJFRC105-10XUAS-IVS-nlstdTomato in } \\
\text { VK00040 }\end{array}$ & $\begin{array}{l}\text { Jack Etheredge; } \\
\text { Etheredge, } 2017\end{array}$ & $\mathrm{~N} / \mathrm{A}$ \\
\hline $\begin{array}{l}\text { D. melanogaster: } \mathrm{w}[1118] ; \mathrm{P}\{\mathrm{y}[+\mathrm{t} 7.7] \\
\mathrm{w}[+\mathrm{mC}]=\mathrm{GMR} 72 \mathrm{~F} 11-\mathrm{GAL} 4\} \mathrm{attP} 2\end{array}$ & $\begin{array}{l}\text { Bloomington } \\
\text { Drosophila Stock } \\
\text { Center }\end{array}$ & RRID:BDSC_39786 \\
\hline D. melanogaster. $\mathrm{P}\{\mathrm{GawB}\} T a b 2[201 \mathrm{Y}]$ & $\begin{array}{l}\text { Bloomington } \\
\text { Drosophila Stock } \\
\text { Center }\end{array}$ & RRID:BDSC_4440 \\
\hline $\begin{array}{l}\text { D. melanogaster. } \mathrm{w}[1118] \mathrm{P}\{\mathrm{y}[+\mathrm{t} 7.7] \mathrm{w}[+\mathrm{mC}]=20 X U A S- \\
\text { IVS-CsChrimson.mVenus }\} \text { attP18 }\end{array}$ & $\begin{array}{l}\text { Bloomington } \\
\text { Drosophila Stock } \\
\text { Center }\end{array}$ & RRID: BDSC_55134 \\
\hline \multicolumn{3}{|l|}{ Software and Algorithms } \\
\hline polyseq & This paper & $\begin{array}{l}\text { https://github.com/i } \\
\text { wittenbach/polyseq }\end{array}$ \\
\hline bcl2fastq & Ilumina & $\begin{array}{l}\text { https://support.illumi } \\
\text { na.com/sequencing/ } \\
\text { sequencing_softwar } \\
\text { e/bcl2fastq- } \\
\text { conversion- } \\
\text { software.html; RRID: } \\
\text { SCR_015058 }\end{array}$ \\
\hline
\end{tabular}


bioRxiv preprint doi: https://doi. org/10.1101/785931; this version posted January 16,2020 . The copyright holder for this preprint (which was not certified by peer review) is the author/funder, who has granted bioRxiv a license to display the preprint in perpetuity. It is made available under aCC-BY-NC-ND 4.0 International license.

\begin{tabular}{|c|c|c|}
\hline Cell Ranger & 10x Genomics & $\begin{array}{l}\text { https://support.10xge } \\
\text { nomics.com/single- } \\
\text { cell-gene- } \\
\text { expression/software/ } \\
\text { overview/welcome }\end{array}$ \\
\hline Seurat & Satija et al., 2015 & $\begin{array}{l}\text { https://satijalab.org/s } \\
\text { eurat/; RRID: } \\
\text { SCR_007322 }\end{array}$ \\
\hline TensorFlow & Google Brain Team & $\begin{array}{l}\text { https://www.tensorfl } \\
\text { ow.org/install; } \\
\text { RRID:SCR_016345 }\end{array}$ \\
\hline Moncole3 & Cao et al., 2019 & $\begin{array}{l}\text { https://cole-trapnell- } \\
\text { lab.github.io/monocl } \\
\underline{\text { e3/ }}\end{array}$ \\
\hline Garnett & Pliner et al., 2019 & $\begin{array}{l}\text { https://cole-trapnell- } \\
\text { lab.github.io/garnett/ }\end{array}$ \\
\hline topGO & $\begin{array}{l}\text { Alexa and } \\
\text { Rahnenfuhrer J, } 2019\end{array}$ & $\begin{array}{l}\text { https://bioconductor. } \\
\text { org/packages/release } \\
\text { /bioc/html/topGO.ht } \\
\text { ml; } \\
\text { RRID:SCR_014798 }\end{array}$ \\
\hline Fiji & PMID:22743772 & $\begin{array}{l}\text { http://fiji.sC; } \\
\text { RRID:SCR_002285 }\end{array}$ \\
\hline \multicolumn{3}{|l|}{ Other } \\
\hline Jupyter notebooks of data analysis used in this paper & This paper & $\begin{array}{l}\text { https://github.com/j } \\
\text { wittenbach/polyseq }\end{array}$ \\
\hline
\end{tabular}


868 Supplemental Information titles and legends:

869

A

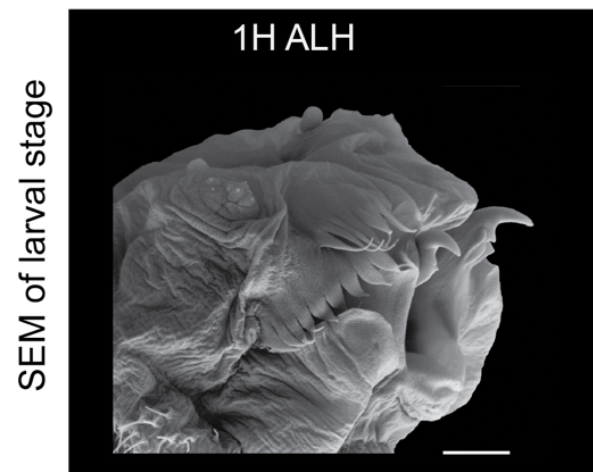

B

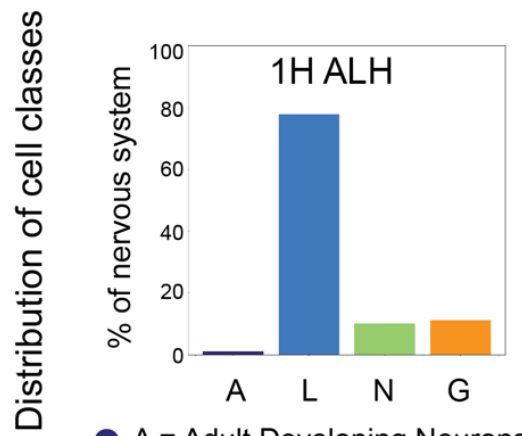

$24 \mathrm{H} \mathrm{ALH}$
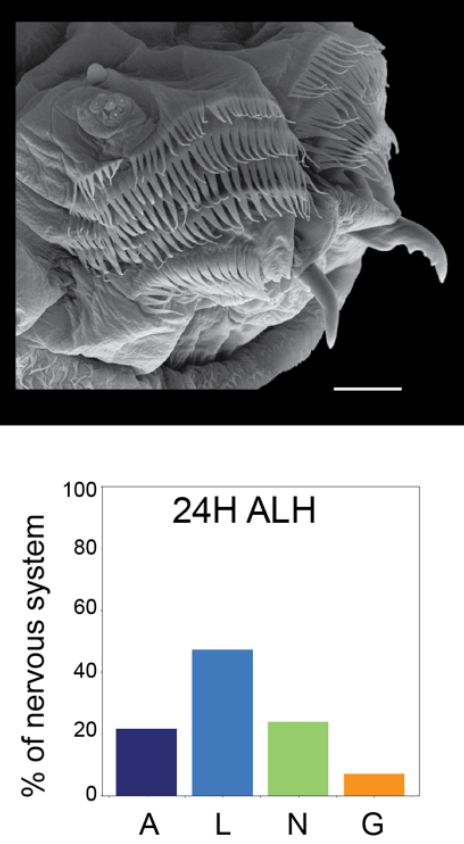

$L=$ Larval Functional Neurons

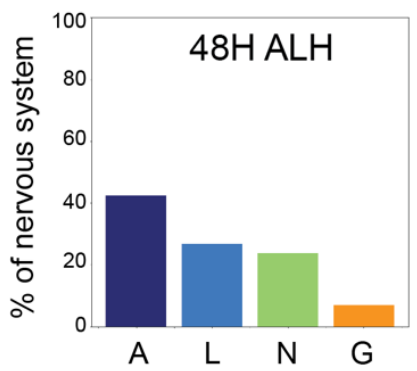

$A=$ Adult Developing Neurons

$N=$ Neural Stem Cells

$\mathrm{G}=$ Glia

871 Figure S1. Single cell transcriptomic atlas of the larval nervous system across

872 developmental stages. A. Scanning electron microscopy (SEM) image of larval

873 anatomy during development. Three developmental stages were sequenced separately

874 to build age specific atlases (Scale bar $=10 \mathrm{~m}$ for $1 \mathrm{H}, 20 \mathrm{~m}$ for $24 \mathrm{H}$ and $40 \mathrm{~m}$ for 48

$875 \mathrm{H})$. Larval size and elaboration of mouth hooks continues during this developmental

876 period. B. Distribution of cell classes. Just after hatching (1 hour after larval hatching

$877(\mathrm{ALH}))$, there is one primary central cluster of neurons. Neuron classes are

878 recognizable, including cholinergic neurons, motor neurons, astrocyte-like glia, and

879 neuroblasts. At 24 hours ALH multiple main groups of neurons are recognizable with

880 markers consistent with an increase in neuroblasts and ganglion mother cells (GMCs).

881 In addition, there are large groups of neurons, here labeled "developing adult neurons"

882 which have neuron markers but few or no genes expressed for synaptic transmitters

883 and receptors. This is consistent with the large burst of neurons born at this point in 
884 development which lay dormant until adult life. At 48 hours ALH the functional larval and

885 developing adult populations are still identifiable.

A $\quad$ B

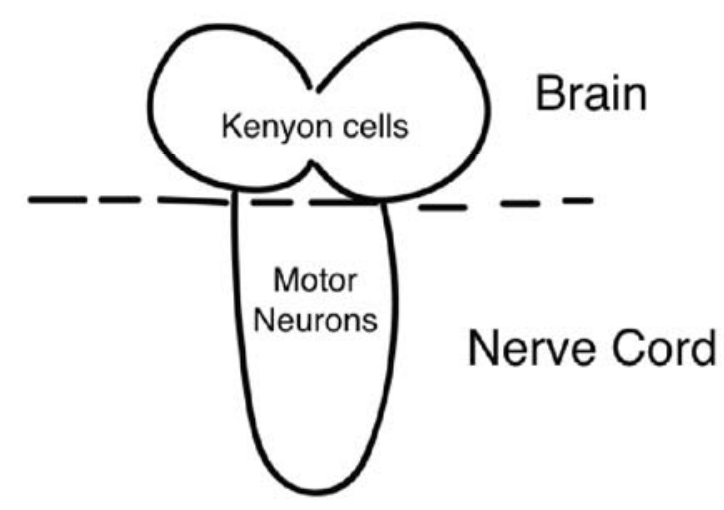

expression profiles

Brain or nerve cord classification

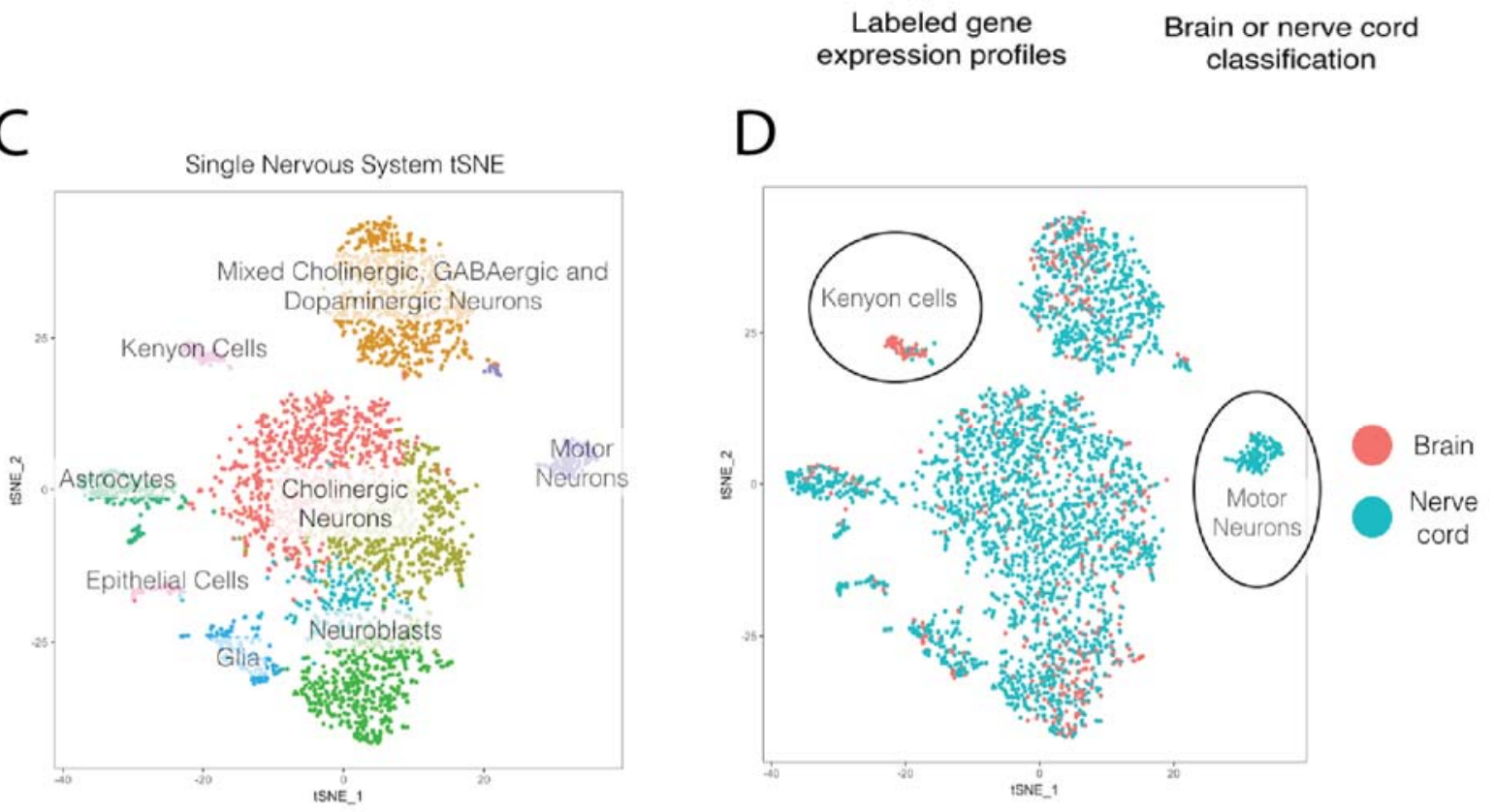

C

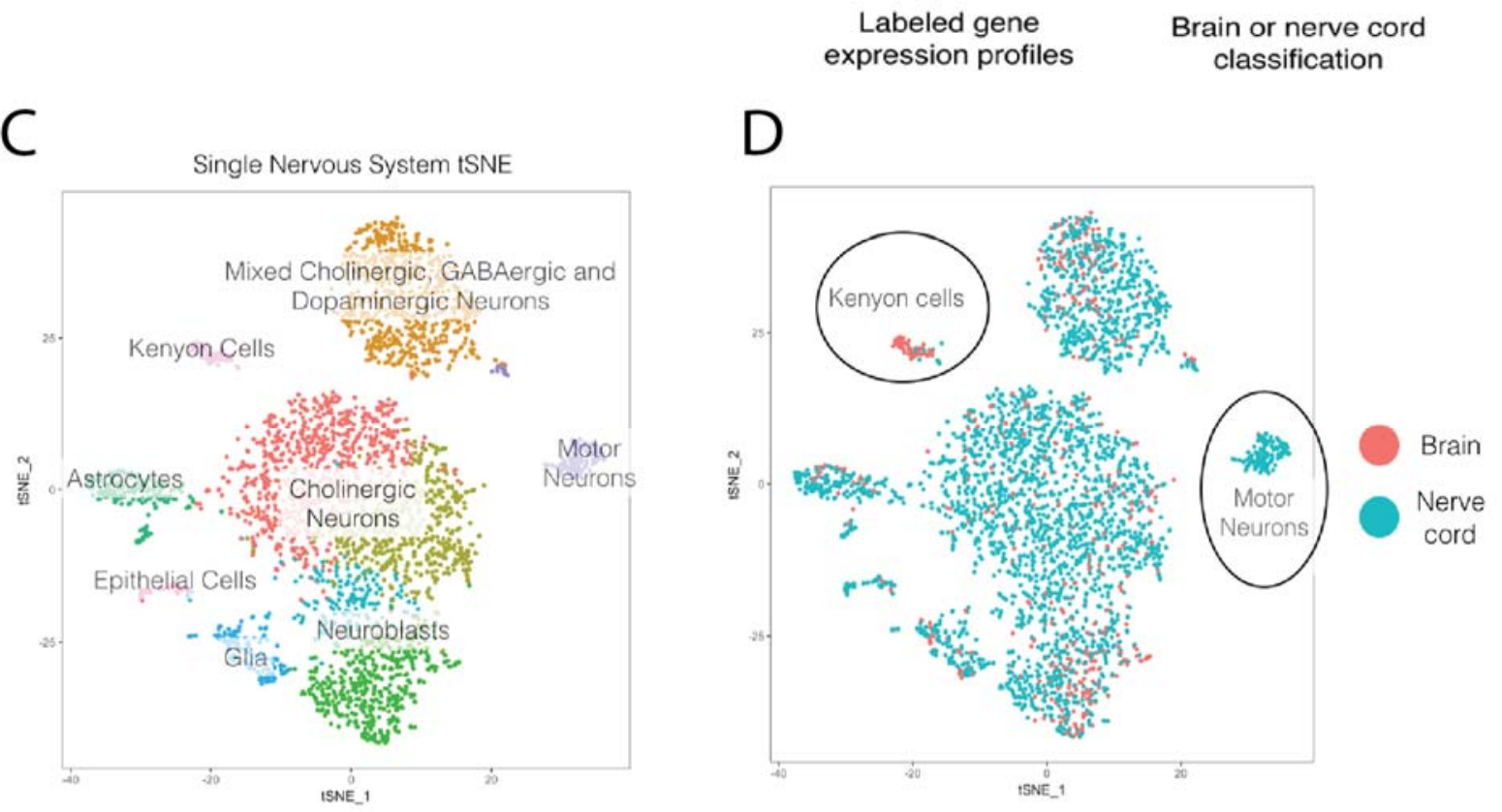

Neural Network

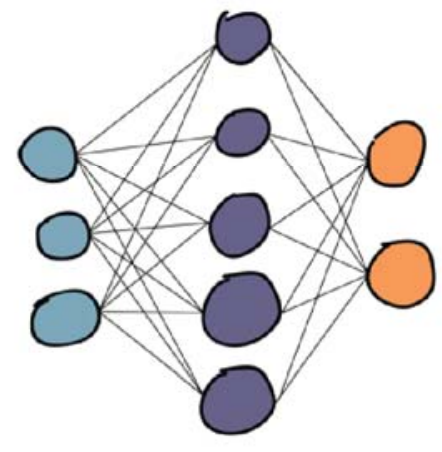

Input Hidden Layers Output

888 Fig S2. Machine learning separates brain and VNC neurons.

889 We dissected the brain from the nerve cord and sequenced the RNA from each

890 population separately. This provided ground truth labels which we could then feed into

891 (B) a neural network to train a classifier to predict spatial origin from the brain of the 
892 VNC. C. We then used our classifier (built on separate data) to predict the brain or VNC

893 origin of cells from a nervous system that was sequenced in one sample (no brian or

894 VNC dissection). D. The classifier correctly separated brain from VNC cells in an intact

895 sample. Most clusters were appropriately mixed brain and VNC cells; however, one

896 pure VNC population (motor neurons) and one pure brain population (Kenyon cells)

897 were appropriately labeled by our machine learning classifier.

898

899

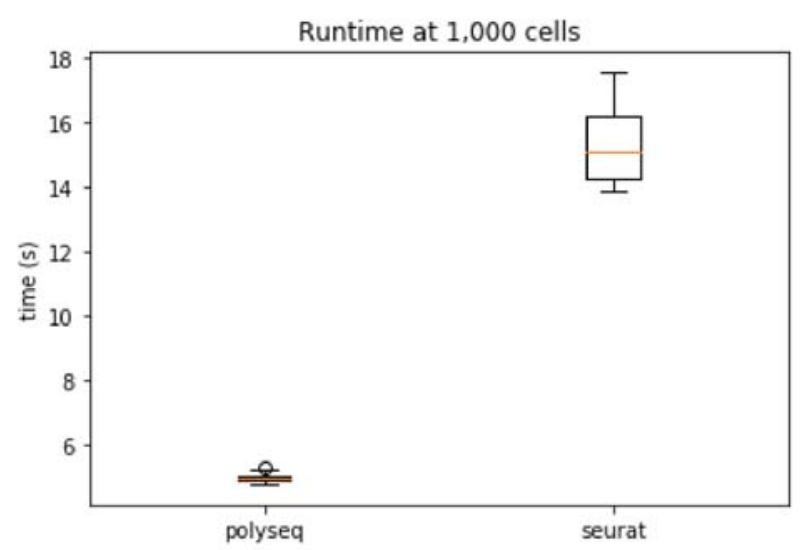

900

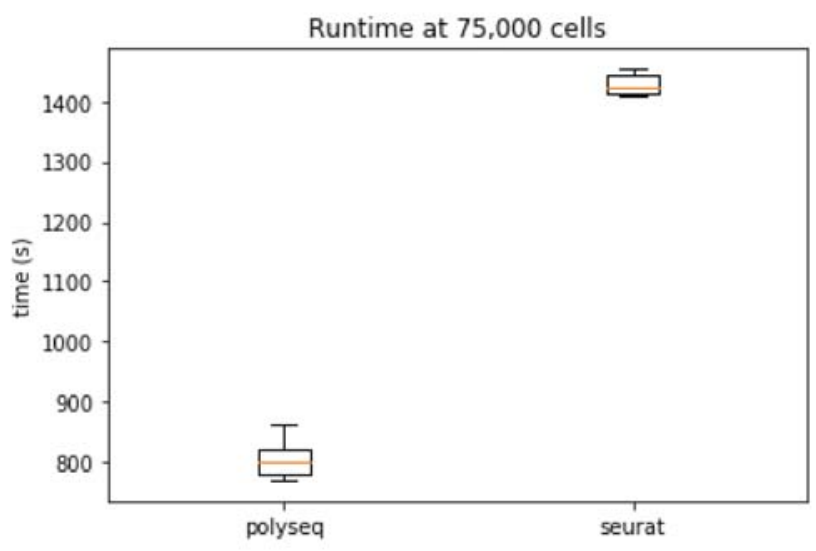

901 Figure S3. Runtime for a typical pipeline to analyze single cell data in Seurat (R)

902 versus polyseq (python).

903 Equivalent analysis pipelines were built in Seurat and polyseq to analyze single cell

904 RNAseq data for datasets of 1,000 cells and 75,000 cells on a single laptop running

905 Mac OS with 16GB RAM and a 2.6 GHz Intel Core i7. Polyseq outperformed Seurat for 
bioRxiv preprint doi: https://doi org/10 1101/785931. this version posted January 16,2020 . The copyright holder for this preprint (which was not certified by peer review) is the author/funder, who has granted bioRxiv a license to display the preprint in perpetuity. It is made available under aCC-BY-NC-ND 4.0 International license.

906 both small and medium datasets. Jupyter notebooks used for testing that contain code

907 for Seurat and polyseq is available upon request.

908

909

Annotated Atlas of the Complete Larval Nervous System

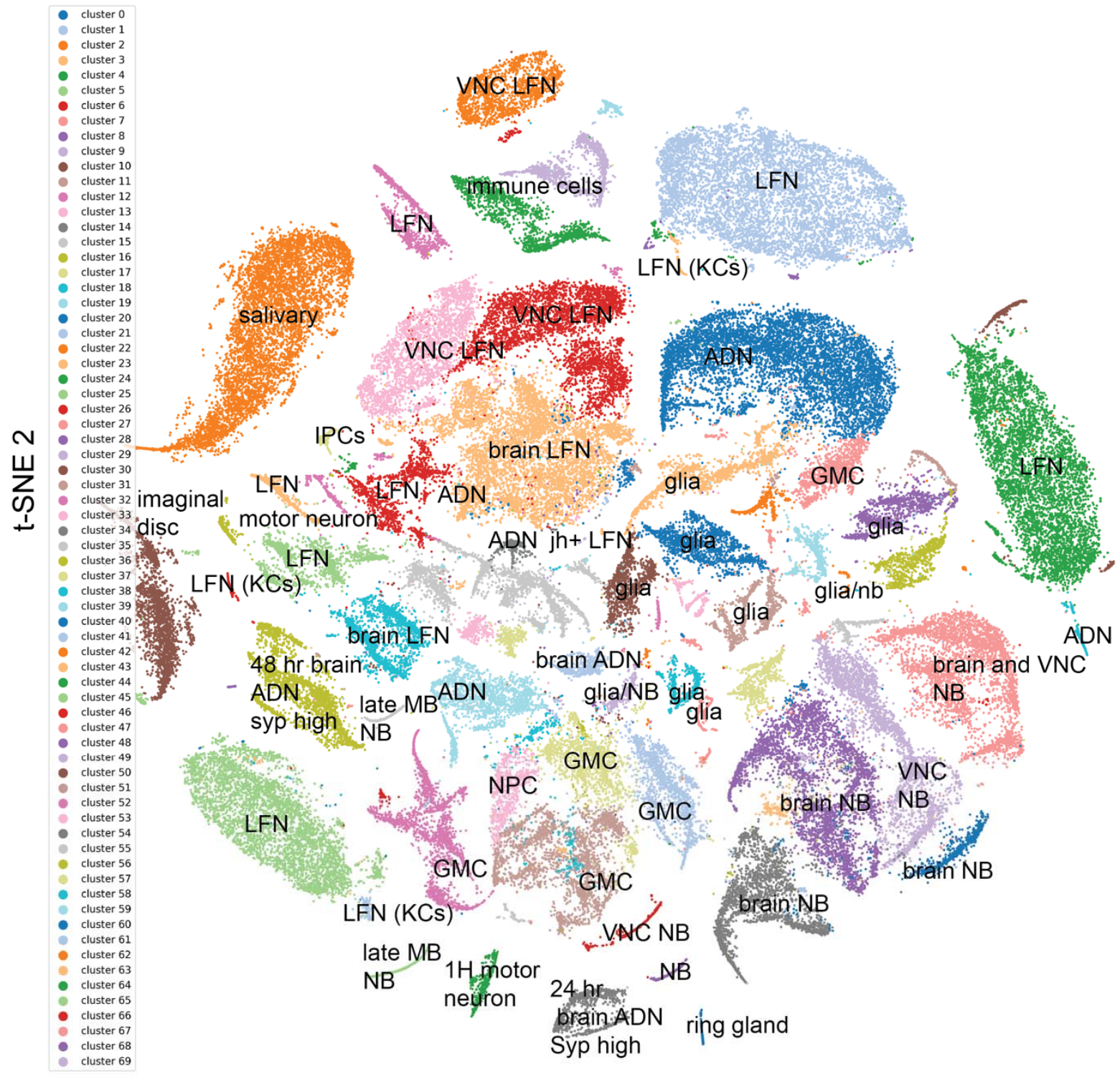

911 Figure S4. Labeled atlas of the complete larval nervous system. The atlas split into

91270 clusters, which are labeled by color and class or more specific name. The top genes 
bioRxiv preprint doi: https://doi org/10.1101/785931. this version posted January 16, 2020. The copyright holder for this preprint (which was not certified by peer review) is the author/funder, who has granted bioRxiv a license to display the preprint in perpetuity. It is made available under aCC-BY-NC-ND 4.0 International license.

913 which define each cluster, along with the mean expression within the cluster, the 914 expression outside the cluster, and the p-value can be found in Table S1.

915 
bioRxiv preprint doi: https://doi.org/10.1101/785931; this version posted January 16, 2020. The copyright holder for this preprint (which was not certified by peer review) is the author/funder, who has granted bioRxiv a license to display the preprint in perpetuity. It is made available under aCC-BY-NC-ND 4.0 International license.
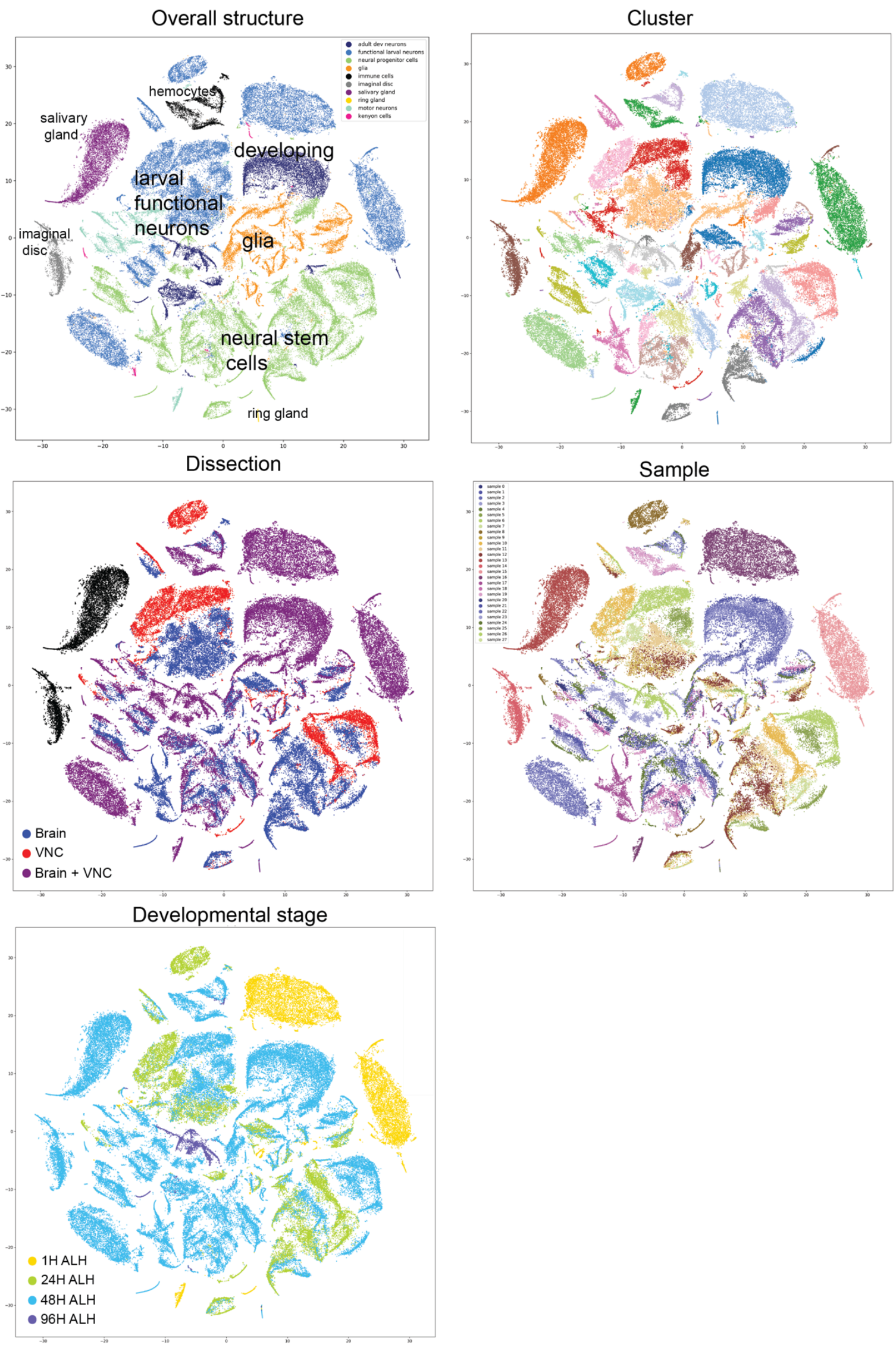
917 Figure S4. Complete single-cell transcriptomic atlas of the larval central nervous

918 system colored by structure, cluster, dissection, sample, and developmental

919 stage. The complete atlas, described in Figures 4 and S4, colored by key

920 characteristics of the dataset. The first provides an overall structure of the cell classes

921 and where they are found in t-SNE space. The cluster coloring provides information

922 about location for each of the 70 clusters. The dissection splits the data into how the

923 data was collected - whether the sample contained only brain, only VNC, or both. The

924 sample t-SNE provides information about individual 10X genomics samples. The

925 developmental stage provides information about the age of the larvae at collection. 
A

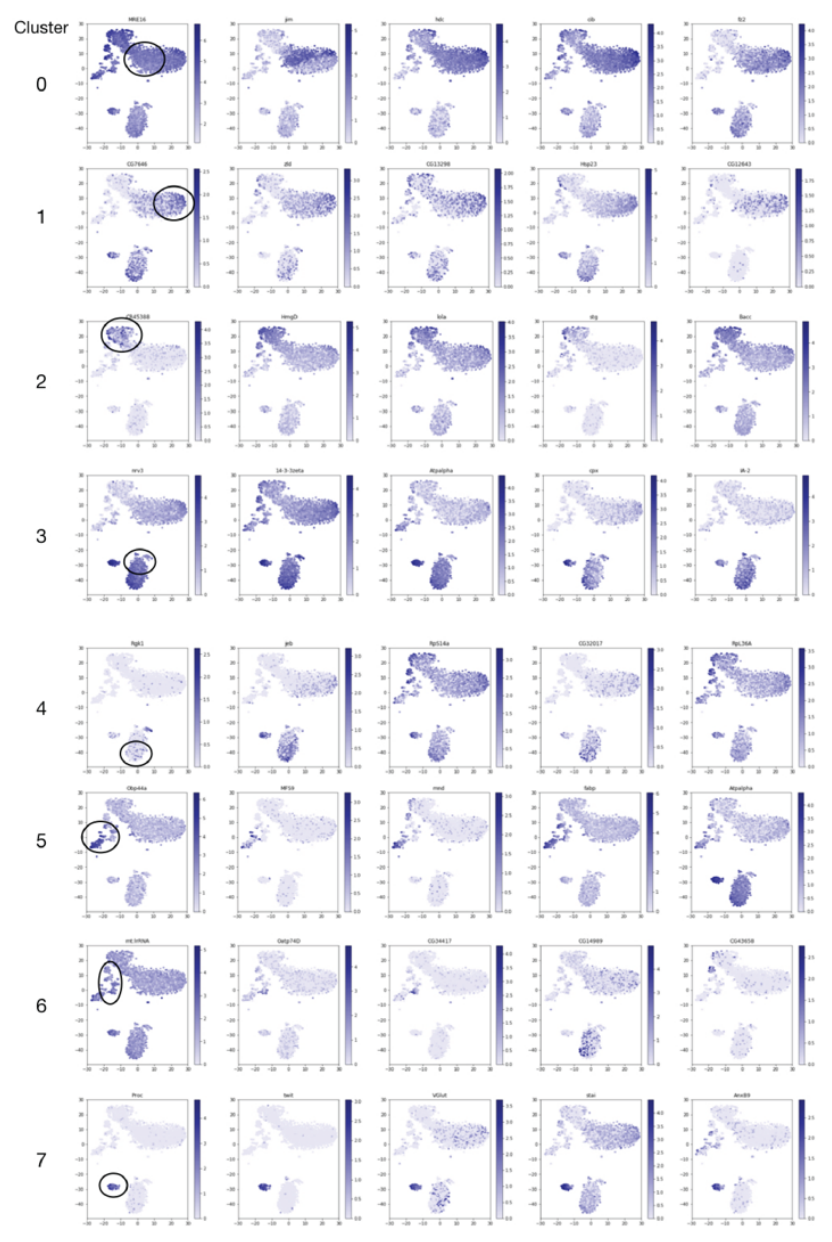

B

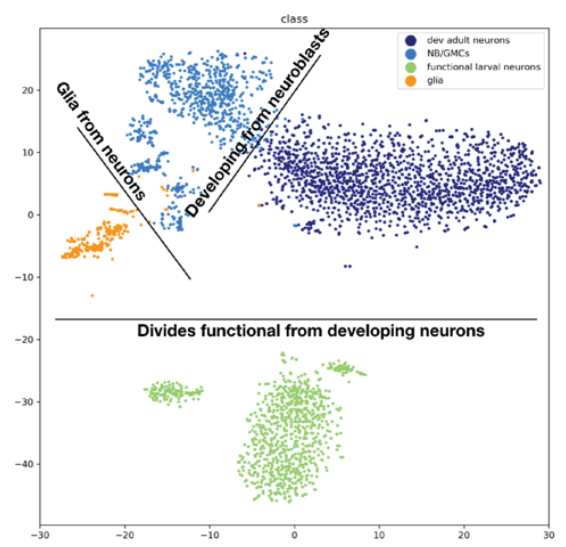

C

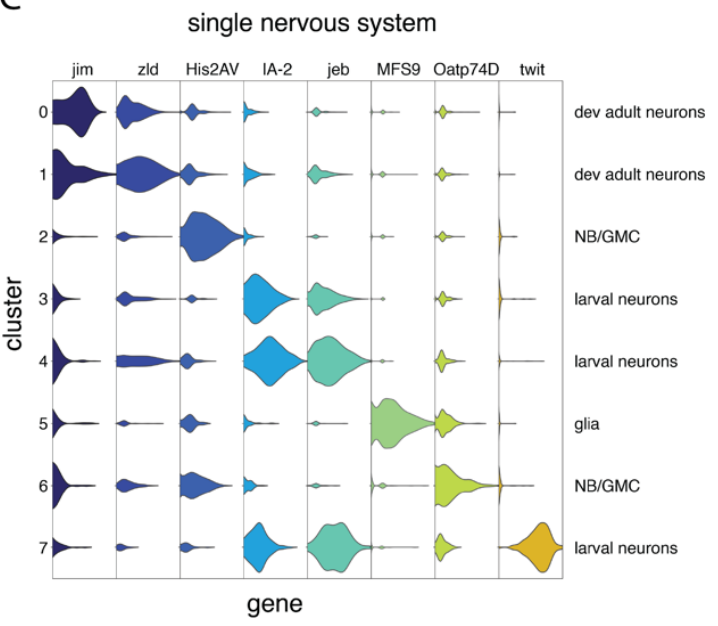

933 Figure S6. Complete nervous system atlas from an individual animal.

934 A. t-SNE of the complete single nervous system with cell clusters colored by gene

935 expression of the top genes in each cluster. For each cluster in A there is a combination

936 of genes which separate the clusters into recognizable molecular cell types and cell

937 classes. B. Lines can be drawn in the t-SNE space that separates each of the cell

938 classes we define here (adult developing neurons, functional larval neurons, neural

939 stem cells, and glia). C. Violin plot of characteristic genes which separate each of the 8

940 top level clusters. 

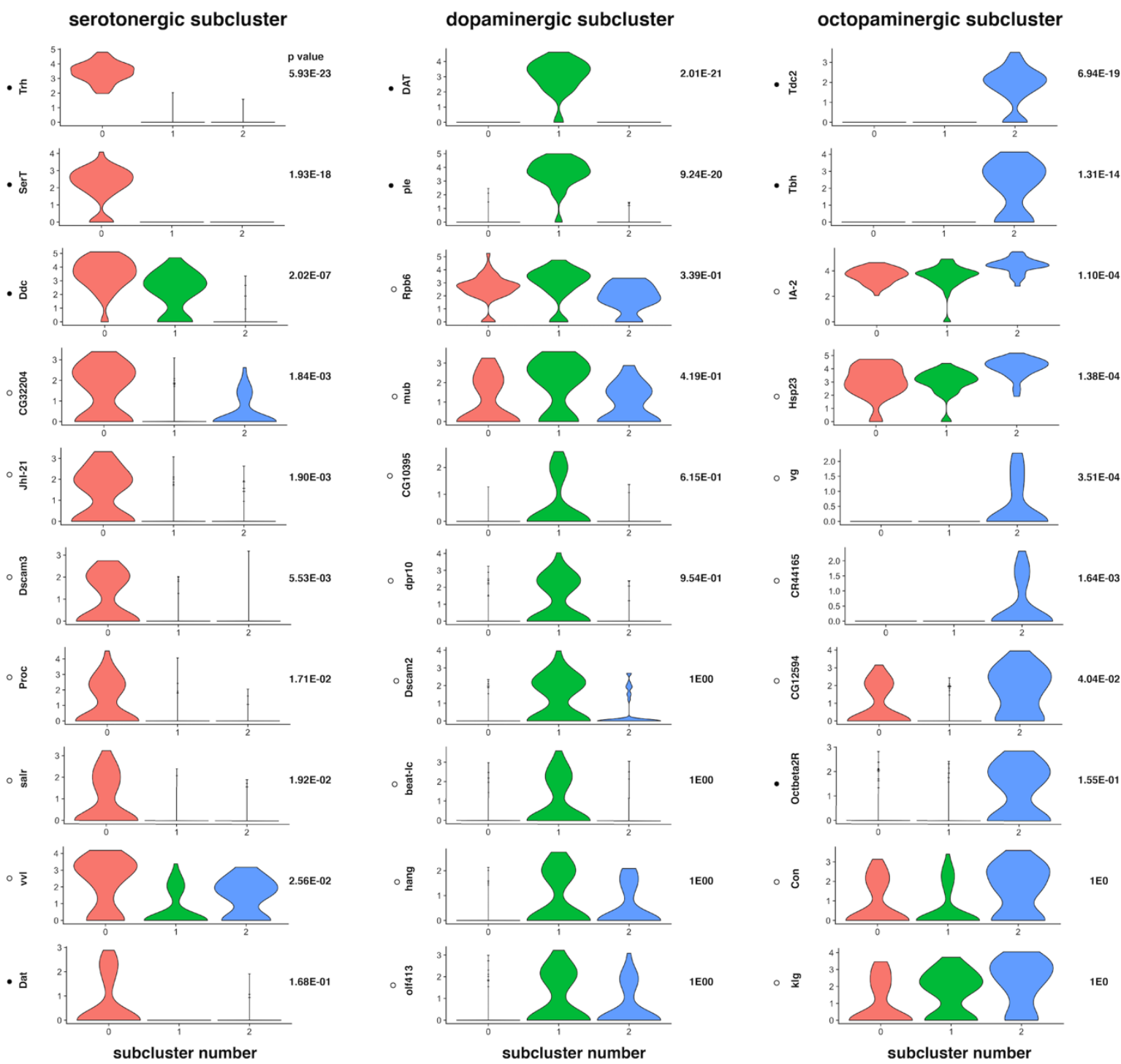

$1.31 \mathrm{E}-14$
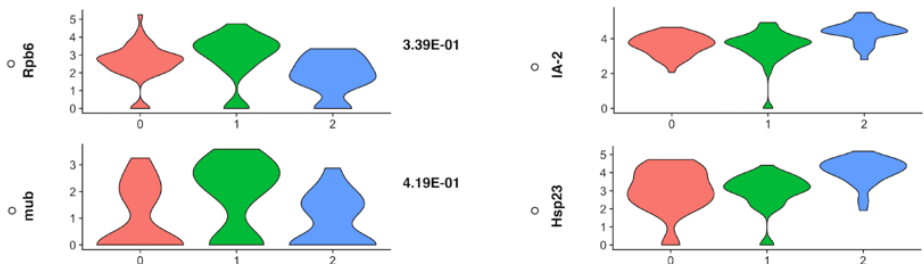

$1.10 \mathrm{E}-04$
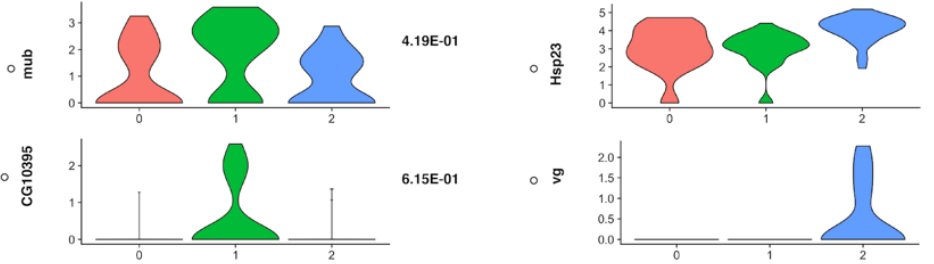

$1.38 \mathrm{E}-04$
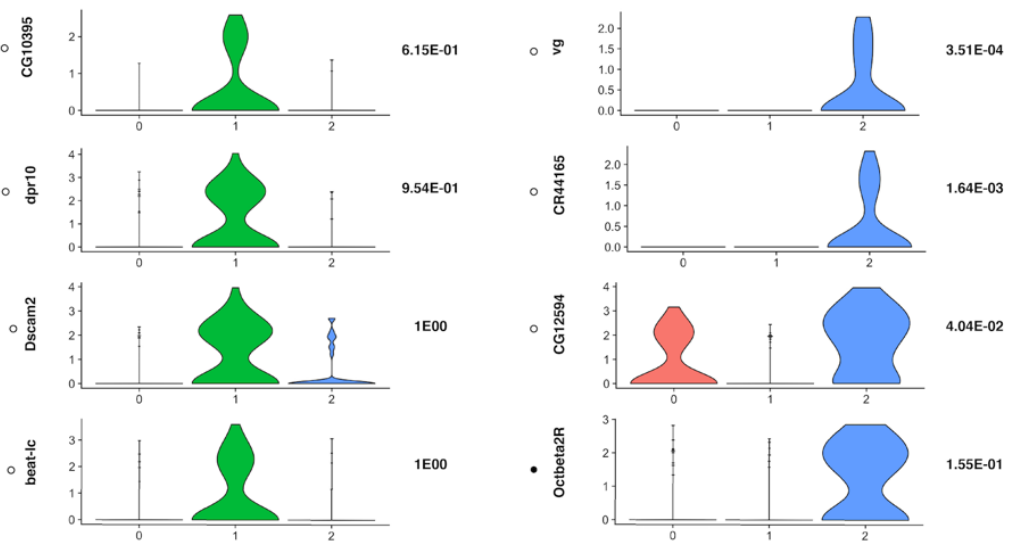

○总
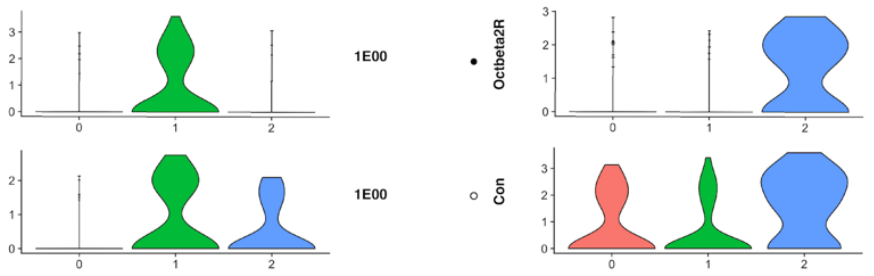

$1.55 \mathrm{E}-01$
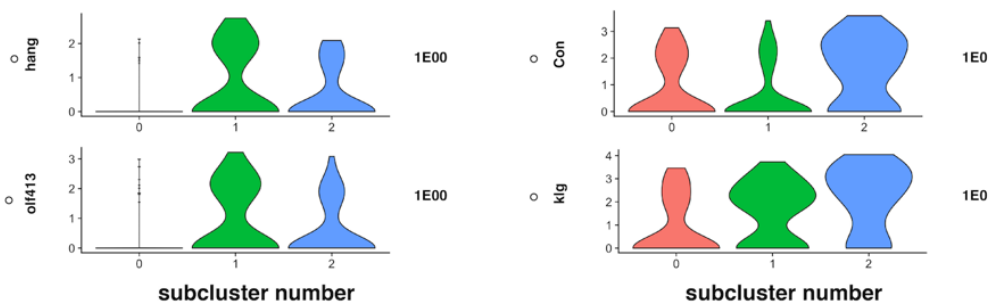

known marker

novel marker

946 Figure S7. Unsupervised clustering separates recognizable serotonergic,

947 dopaminergic, octopaminergic neurons into subclusters with known validated

948 markers and novel markers. A cluster of cells was discovered using unsupervised

949 machine learning techniques with markers indicative of dopaminergic cells. This cluster

950 was separated and clustered once more, revealing three separate clusters with gene

951 markers indicating a serotonergic subcluster, a dopaminergic subcluster, and an

952 octopaminergic subcluster. The top genes that separate these clusters from one 
953 another were then computed and violin plots were generated. Known markers were the

954 top genes for each subcluster and gave them recognizable identity - for example,

955 tryptophan hydroxylase (Trh), which is used to synthesize serotonin from tryptophan,

956 and serotonin transporter (SerT) were the top genes for the first subcluster, which could

957 then be appropriately labeled containing serotonergic cells. In addition to known gene

958 markers, new makers were also discovered for each group of cells.

A

Control NPLP2 expression
NPLP2

pale

brain

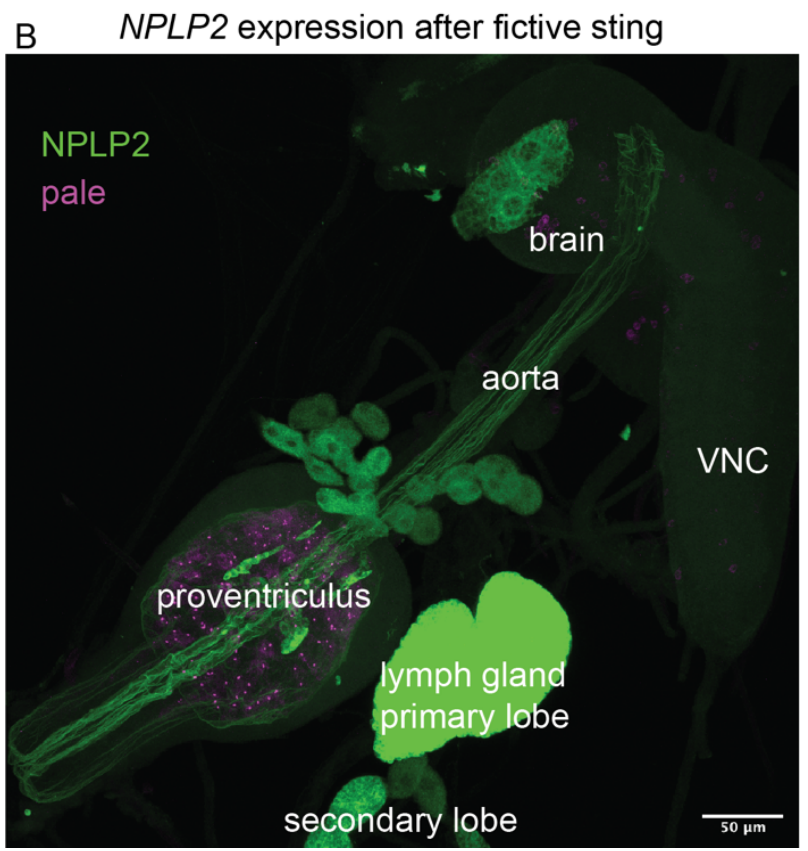

Figure S8: NPLP2 expression is increased in the proventriculus and the brain after fictive sting. An RNA-FISH probe was designed for NPLP2 and pale (ple) to investigate the strong increased signal of NPLP2 following the fictive sting. In the brain lobes, the size of the NPLP2-positive cells is much larger. In the proventriculus, where immune cells emerge, there appear to be more NPLP2 positive cells emerging in the case after fictive sting, suggesting an immune reaction releated to the activation of 
969 Table S1. Atlas of cell types in the complete larval nervous system.

970 The top genes for the 70 cell type clusters are provided with the mean expression inside

971 the cluster, mean expression outside the cluster, and p-value. These clusters

972 correspond to Figure 4 and Supplementary Figure S4.

973

974 Table S2. Gene modules that characterize neural precursor cells over

975 development. Differential gene expression was used to compute gene modules in the

976 Monocle3 R package. The modules characterize early, intermediate, and late neural

977 precursor cell populations (Figure 3).

978

979 Table S3. Fictive sting full nervous system atlas.

980 The top genes for the 14 cell type clusters obtained from animals that were fictively

981 stung and controls. Tables include the top genes for each cluster, the mean expression

982 inside the cluster, the mean expression outside the cluster, and the $p$-value. These

983 clusters correspond to Figure 7E-F.

984

985 Table S4. KC overactivation full nervous system atlas.

986 The top genes for the 14 cell type clusters obtained from animals that had KCs

987 repeatedly activated and controls. Tables include the top genes for each cluster, the

988 mean expression inside the cluster, the mean expression outside the cluster, and the $\mathrm{p}$ -

989 value. These clusters correspond to Figure 7G-I.

990

991 Table S5: RNA-FISH probe sequences. RNA sequeces of probes built to label AstC-

$992 R 2$, Hug, and NPLP2 transcripts.

993 Movie S1. Z-stacks through RNA-FISH of AstC in insulin-producing cells.

994 Z stacks are shown through the confocal stack of a brain in which the IPCs are labeled 995 with a fluorescent HaloTag ligand (Magenta), and AstC-R2 mRNA is detected by FISH

996 (green), bar 10 1 m. This movie corresponds to Flgure 5 in the main text. 
998 Movie S2. Single-molecule imaging to correlate between single-molecule FISH 999 and scRNAseq.

1000 Cells were identified with coexpression of AstC (green) and vGlut (magenta) in the

1001 whole brain. This movie corresponds to Figure 6 in the main text and shows a view

1002 through z-stacks of BB-SIM images of AstC and vGlut mRNA FISH channels.

1003

1004

\section{References:}

1005

Ahrens, M. B., Orger, M. B., Robson, D. N., Li, J. M., \& Keller, P. J. (2013). Whole-brain

1006 functional imaging at cellular resolution using light-sheet microscopy. Nature

1007 methods, 10(5), 413.

1008

1009

Avalos, C. B., Maier, G. L., Bruggmann, R., \& Sprecher, S. G. (2019). Single cell

1010 transcriptome atlas of the Drosophila larval brain. eLife, 8.

1011

1012

Bakker, K. (1959). Feeding period, growth, and pupation in larvae of Drosophila

1013

1014

1015 melanogaster. Entomologia Experimentalis et Applicata, 2(3), 171-186.

1016

Berck ME, Khandelwal A, Claus L, Hernandez-Nunez L, Si G, Tabone CJ, Li F, Truman

1017 JW, Fetter RD, Louis M et al.: The wiring diagram of a glomerular olfactory system. Elife

1018

1019 2016, 5.

1020

Borst, A. (2014). Fly visual course control: behaviour, algorithms and circuits. Nature Reviews Neuroscience, 15(9), 590.

1021

1022

Cao, J., Spielmann, M., Qiu, X., Huang, X., Ibrahim, D. M., Hill, A. J., ... \& Trapnell, C.

1023

1024 (2019). The single-cell transcriptional landscape of mammalian organogenesis. Nature, 566(7745), 496.

1025

1026

Chhetri, R. K., Amat, F., Wan, Y., Höckendorf, B., Lemon, W. C., \& Keller, P. J. (2015).

1027

1028

1029

1030 resolution. Nature methods, 12(12), 1171.

1031

1032

1033

Croset, V., Treiber, C. D., \& Waddell, S. (2018). Cellular diversity in the Drosophila midbrain revealed by single-cell transcriptomics. Elife, 7, e34550.

1034

Davie, K., Janssens, J., Koldere, D., De Waegeneer, M., Pech, U., Kreft, Ł., ... \&

1035 Poovathingal, S. (2018). A single-cell transcriptome atlas of the aging Drosophila 1036 brain. Cell, 174(4), 982-998. 
1037 Diaz, M.M. et al. Allatostatin-C/AstC-R2 Is a Novel Pathway to Modulate the Circadian Activity Pattern in Drosophila. Curr. Biol. 29, 13-22 (2019)

Doe, C. Q. (2017). Temporal patterning in the Drosophila CNS. Annual review of cell and developmental biology, 33, 219-240.

Eichler, K, et al. "The complete connectome of a learning and memory centre in an insect brain." Nature 548.7666 (2017): 175. Zlatic, M. (2019). Multilevel feedback architecture for adaptive regulation of learning in the insect brain. bioRxiv, 649731.

1051

Etheredge, J. (2017). Transcriptional profiling of Drosophila larval ventral nervous system hemilineages (Doctoral dissertation, University of Cambridge). RNA transcripts in situ. Science, 280(5363), 585-590. midline cells reveals diverse peptidergic properties and a role for castor in neuronal differentiation. Developmental biology, 372(1), 131-142.

1061

Fossett, N., \& Schulz, R. A. (2001). Functional conservation of hematopoietic factors in

1062

1063 Drosophila and vertebrates. Differentiation, 69(2-3), 83-90.

1064

1065

1066

Freeman, M. R. (2015). Drosophila central nervous system glia. Cold Spring Harbor perspectives in biology, 7(11), a020552.

1067

1068

1069

1070

1071

1072

1073

Garcia-Campmany, L., Stam, F. J., \& Goulding, M. (2010). From circuits to behaviour: motor networks in vertebrates. Current opinion in neurobiology, 20(1), 116-125.

1074

1075

1076

1077

1078

1079

Gilbert, L. I. (2004). Halloween genes encode P450 enzymes that mediate steroid hormone biosynthesis in Drosophila melanogaster. Molecular and cellular endocrinology, 215(1-2), 1-10.

1080

1081

1082

Grimm, J. B., Muthusamy, A. K., Liang, Y., Brown, T. A., Lemon, W. C., Patel, R., ... \& Lavis, L. D. (2017). A general method to fine-tune fluorophores for live-cell and in vivo imaging. Nature methods, 14(10), 987.

Haghverdi, L., Lun, A. T., Morgan, M. D., \& Marioni, J. C. (2018). Batch effects in singlecell RNA-sequencing data are corrected by matching mutual nearest neighbors. Nature biotechnology, 36(5), 421.

Hartenstein, V., and Campos-Ortega, J.A. (1984). Early neurogenesis in wild-type Drosophila melanogaster. Wilhelm Roux's Arch. Dev. Biol. 193, 308-325. 
1083

1084

1085

1086

1087

1088

1089

1090

1091

1092

1093

1094

1095

1096

1097

1098

1099

1100

1101

1102

1103

1104

1105

1106

1107

1108

1109

1110

1111

1112

1113

1114

1115

1116

1117

1118

1119

1120

1121

1122

1123

1124

1125

1126

1127

Hartenstein, V., Rudloff, E., and Campos-Ortega, J.A. (1987). The pattern of proliferation of the neuroblasts in the wild-type embryo of Drosophila melanogaster. Wilhelm Roux's Arch Dev Bio 198, 264-274.

Helmstaedter M, Briggman KL, Turaga SC, Jain V, Seung HS, Denk W: Connectomic reconstruction of the inner plexiform layer in the mouse retina. Nature 2013, 500:168174.

Hentze, J. L., Carlsson, M. A., Kondo, S., Nässel, D. R., \& Rewitz, K. F. (2015). The neuropeptide allatostatin $A$ regulates metabolism and feeding decisions in Drosophila. Scientific reports, 5, 11680.

Hildebrand DGC, Cicconet M, Torres RM, Choi W, Quan TM, Moon J, Wetzel AW, Scott Champion A, Graham BJ, Randlett O et al.: Whole-brain serial-section electron microscopy in larval zebrafish. Nature 2017, 545:345-349.

Hwang, R. Y., Zhong, L., Xu, Y., Johnson, T., Zhang, F., Deisseroth, K., \& Tracey, W. D. (2007). Nociceptive neurons protect Drosophila larvae from parasitoid wasps. Current Biology, 17(24), 2105-2116.

Jarrell TA, Wang Y, Bloniarz AE, Brittin CA, Xu M, Thomson JN, Albertson DG, Hall DH, Emmons SW: The connectome of a decision-making neural network. Science 2012, 337:437-444.

Jovanic, T., Masson, J. B., Truman, J. W., \& Zlatic, M. (2017). Mapping neurons and brain regions underlying sensorimotor decisions and sequences. bioRxiv, 215236.

Kater, S. B., Murphy, A. D., \& Rued, J. R. (1978). Control of the salivary glands of Helisoma by identified neurones. Journal of Experimental Biology, 72(1), 91-106.

Kater, S. B., Rued, J. R., \& Murphy, A. D. (1978). Propagation of action potentials through electrotonic junctions in the salivary glands of the pulmonate mollusc, Helisoma trivolvis. Journal of Experimental Biology, 72(1), 77-90.

Konopka, R. J., \& Benzer, S. (1971). Clock mutants of Drosophila melanogaster. Proceedings of the National Academy of Sciences, 68(9), 2112-2116.

Konstantinides, N., Kapuralin, K., Fadil, C., Barboza, L., Satija, R., \& Desplan, C. (2018). Phenotypic convergence: distinct transcription factors regulate common terminal features. Cell, 174(3), 622-635.

Kraaijeveld, A. R., \& Godfray, H. C. J. (1997). Trade-off between parasitoid resistance and larval competitive ability in Drosophila melanogaster. Nature, 389(6648), 278. 
1128 Krashes, M. J., DasGupta, S., Vreede, A., White, B., Armstrong, J. D., \& Waddell, S. (2009). A neural circuit mechanism integrating motivational state with memory expression in Drosophila. Cell, 139(2), 416-427. J. W. (2014). A GAL4 driver resource for developmental and behavioral studies on the larval CNS of Drosophila. Cell reports, 8(3), 897-908.

Lionnet, T. et al. A transgenic mouse for in vivo detection of endogenous labeled mRNA. Nat Methods 8, 165-70 (2011). brain of adult Drosophila are regulated by the serotonin 5-HT $1 \mathrm{~A}$ receptor. Cellular and Molecular Life Sciences, 69(3), 471-484.

Maaten, L. V. D., \& Hinton, G. (2008). Visualizing data using t-SNE. Journal of machine learning research, 9(Nov), 2579-2605.

Mclnnes, L., Healy, J., \& Melville, J. (2018). Umap: Uniform manifold approximation and projection for dimension reduction. arXiv preprint arXiv:1802.03426.

Meissner, G.W. et al. Mapping Neurotransmitter Identity in the Whole-Mount Drosophila Brain Using Multiplex High-Throughput Fluorescence in Situ Hybridization. GENETICS 211:437-482

Ohyama T, Schneider-Mizell CM, Fetter RD, Aleman JV, Franconville R, Rivera-Alba M, enhances action selection in Drosophila. Nature 2015, 520: 633-639. 
1173 Prevedel, R., Yoon, Y. G., Hoffmann, M., Pak, N., Wetzstein, G., Kato, S., ... \& Vaziri, A. 1174 (2014). Simultaneous whole-animal 3D imaging of neuronal activity using light-field 1175 microscopy. Nature methods, 11(7), 727.

Qiu, X., Mao, Q., Tang, Y., Wang, L., Chawla, R., Pliner, H. A., \& Trapnell, C. (2017). Reversed graph embedding resolves complex single-cell trajectories. Nature methods, 14(10), 979. (2016). Serotonin signaling mediates protein valuation and aging. Elife, 5, e16843. flies: growth and diabetic phenotypes. Science, 296(5570), 1118-1120.

Schindelin, J. et al. Fiji: an open-source platform for biological-image analysis. Nat Methods 9, 676-82 (2012).

Schlegel, P., Texada, M. J., Miroschnikow, A., Schoofs, A., Hückesfeld, S., Peters, M., ... \& Truman, J. W. (2016). Synaptic transmission parallels neuromodulation in a central food-intake circuit. Elife, 5, e16799.

1203

1204

1205

1206

Schwaerzel, Martin, et al. "Dopamine and octopamine differentiate between aversive and appetitive olfactory memories in Drosophila." Journal of Neuroscience 23.33 (2003): 10495-10502.

Scott, K., Brady Jr, R., Cravchik, A., Morozov, P., Rzhetsky, A., Zuker, C., \& Axel, R. (2001). A chemosensory gene family encoding candidate gustatory and olfactory receptors in Drosophila. Cell, 104(5), 661-673.

Selcho, Mareike, et al. "The role of dopamine in Drosophila larval classical olfactory conditioning." PloS one 4.6 (2009): e5897.

Sokolowski, M. B. (2001). Drosophila: genetics meets behaviour. Nature Reviews Genetics, 2(11), 879.

Sorrentino, R. P., Carton, Y., \& Govind, S. (2002). Cellular immune response to parasite infection in the Drosophila lymph gland is developmentally regulated. Developmental biology, 243(1), 65-80. 
Takemura SY, Bharioke A, Lu Z, Nern A, Vitaladevuni S, Rivlin PK, Katz WT, Olbris DJ, Plaza SM, Winston $P$ et al.: A visual motion detection circuit suggested by Drosophila connectomics. Nature 2013, 500:175-181.

Trannoy, S., \& Kravitz, E. A. (2017). Strategy changes in subsequent fights as

1223 consequences of winning and losing in fruit fly fights. Fly, 11(2), 129-138.

1224

Trapnell, C., Cacchiarelli, D., Grimsby, J., Pokharel, P., Li, S., Morse, M., ... \& Rinn, J. L. (2014). The dynamics and regulators of cell fate decisions are revealed by pseudotemporal ordering of single cells. Nature biotechnology, 32(4), 381.

Truman, J. W. (2005). Hormonal control of insect ecdysis: endocrine cascades for coordinating behavior with physiology. Vitamins \& Hormones, 73, 1-30.

Truman, J. W., \& Bate, M. (1988). Spatial and temporal patterns of neurogenesis in the central nervous system of Drosophila melanogaster. Developmental biology, 125(1), 145-157.

Truman, J.W., Taylor, B.J., and Awad, T.A. (1993). Formation of the adult nervous system. In The Development of Drosophila melanogaster Vol II, M. Bate and A.M. Arias, eds. (Cold Spring Harbor, NY: Cold Spring Harbor Laboratory Press), pp. 1245-1275.

Vladimirov, N., Wang, C., Höckendorf, B., Pujala, A., Tanimoto, M., Mu, Y., ... \& Koyama, M. (2018). Brain-wide circuit interrogation at the cellular level guided by online analysis of neuronal function. Nature methods, 15(12), 1117.

Vogelstein, J. T., Park, Y., Ohyama, T., Kerr, R. A., Truman, J. W., Priebe, C. E., \& Zlatic, M. (2014). Discovery of brainwide neural-behavioral maps via multiscale unsupervised structure learning. Science, 344(6182), 386-392.

White JG, Southgate E, Thomson JN, Brenner S: The structure of the nervous system of the nematode Caenorhabditis elegans. Philos Trans R Soc Lond B Biol Sci 1986, 314:1-340.

Williamson, M., Lenz, C., Winther, M. E., Nässel, D. R., \& Grimmelikhuijzen, C. J. (2001). Molecular cloning, genomic organization, and expression of a B-type (crickettype) allatostatin preprohormone from Drosophila melanogaster. Biochemical and biophysical research communications, 281(2), 544-550. with glutamate receptors, impacts NMJ physiology, and influences locomotor activity in 
bioRxiv preprint doi: https://doi org/10.1101/785931. this version posted January 16,2020 . The copyright holder for this preprint (which was not certified by peer review) is the author/funder, who has granted bioRxiv a license to display the preprint in perpetuity. It is made available under aCC-BY-NC-ND 4.0 International license.

1262 Ziegler, A. B., Manière, G., \& Grosjean, Y. (2018). Jhl-21 plays a role in Drosophila 1263 insulin-like peptide release from larval IPCs via leucine transport. Scientific reports, 8(1), 12641908. 